\title{
Probability-Based Sensitivity of Service Life of Chloride-Attacked Concrete Structures with Multiple Cover Concrete Repairs
}

\begin{abstract}
Aruz Petcherdchoo
Associate Professor, Department of Civil Engineering, Faculty of Engineering,

King Mongkut's University of Technology North Bangkok, Bangkok 10800, Thailand

Correspondence should be addressed to Aruz Petcherdchoo; aruz.p@eng.kmutnb.ac.th

Received 6 July 2018; Revised 28 September 2018; Accepted 22 October 2018; Published 4 December 2018

Academic Editor: Constantin Chalioris

Copyright ( $\odot 2018$ Aruz Petcherdchoo. This is an open access article distributed under the Creative Commons Attribution License, which permits unrestricted use, distribution, and reproduction in any medium, provided the original work is properly cited.

This paper presents probabilistic and sensitivity analysis of service life (or time to repairs) for attaining corrosion-free condition of concrete structures under chloride attack. Four groups of probabilistic parameters are determined, i.e., (1) time-dependent chloride content, (2) mean and median of corrosion initiation and repair application times, (3) percent confidence of repairs, and (4) total expected number of repairs. To achieve this, this paper proposes a computational approach and probabilistic data. The proposed approach, which combined the Latin Hypercube technique with the Crank-Nicolson-based finite difference approach, is developed for predicting probabilistic chloride diffusion in concrete with repairs by cover concrete replacement. Probabilistic data of four governing random variables (surface chloride, diffusion coefficient, concrete cover depth, and critical chloride) and six repair strategies for corrosion-free condition are introduced. Numerical assessment is then shown. From the study, it is revealed that the reduction of the amount of chloride ions at the threshold depth due to using higher depth of cover concrete repairs is better than that using higher quality of repair materials. However, the excessive depth of repairs is not always recommended due to another control factor, such as the immediate amount of chloride ions at the repair depth, cost of repairs, etc. From the sensitivity analysis, the cover depth is found to be the most important parameter in the design of chloride-attacked concrete structures to extend the corrosion initiation and repair application times and to reduce the total expected number of repairs.
\end{abstract}

\section{Introduction}

The time-dependent deterioration of civil structures was mostly due to the result of aging of materials, continuous use, overloading, aggressive exposure conditions, lack of sufficient maintenance, and difficulties encountered in proper inspection methods [1]. Chloride attack by diffusion was not only categorized as aggressive exposure conditions for the deterioration of concrete structures located in marine environment, but also considered as one of the most concerning issues for long-term durability of reinforced concrete structures [2]. Whenever the threshold amount of diffused chloride ions at reinforcement was reached, a thin oxide layer so called "passivation film" could be broken down [3]. This may initiate reinforcement corrosion that subsequently leads to three significant phenomena: reduction of the cross-sectional area of reinforcement, loss of bonds between concrete and reinforcement $[4,5]$, and concrete cracking. These three phenomena can possibly result in severe structural deterioration. As a result, the diffusion of chloride ions and the reinforcement corrosion not only adversely affect the safety and serviceability of concrete structures, but also shorten their service life [6]. However, in real practice, severe structural deterioration is not preferable due to the risk of human life. To avoid such kind of deterioration, there are two main remedial approaches: use of durable concrete for reinforcement protection [7-9] and application of appropriate repair and maintenance [10-12]. For the latter, there are many kinds of maintenance actions in the market $[13,14]$. To efficiently apply these actions, maintenance (or repair) application times, such as the time prior to reinforcement corrosion $[15,16]$, are of significance. Therefore, a method to predict the appropriate repair application time, which was occasionally defined as service life $[17,18]$, is required. 
In studying the service life and the repair application time of concrete structures under chloride attack, a quantitative assessment is preferable $[19,20]$. The diffusion theory based on Fick's second law can be used to predict the penetration of chloride ions through concrete structures. In the study of researchers [21-23], if the attack of chloride ions (in terms of surface chloride) and the resistance of concrete (in terms of diffusion coefficient) were both assumed constant, the one-dimensional partial differential equation of Fick's second law could analytically be solved and used to predict the service life. However, these studies are based on deterministic data that are not suitable for considering a group of concrete structures, in which uncertainties play an important role. Moreover, even an individual concrete structure itself contains uncertainties in terms of surface chloride, diffusion coefficient, concrete cover depth, and critical chloride value. Hence, several researchers carried out probabilistic studies on service life prediction as follows. In 2006, Zhang and Lounis [24] performed a sensitivity analysis on the diffusion-based corrosion initiation model for reinforced concrete structures built in chloride-laden environments by using analytical differentiation techniques. They found that the time to corrosion initiation for conventional carbon steels was most sensitive to concrete cover depth, followed by chloride diffusion coefficient. However, the time to corrosion initiation for corrosion-resistant steels was most sensitive to the surface chloride concentration and chloride threshold level, followed by the concrete cover depth and chloride diffusion coefficient. Later, BastidasArteaga et al. [25] utilized a stochastic approach for determining the influence of weather conditions and global warming on chloride ingress into concrete. In their study, a simplified model of temperature and humidity including seasonal variations and global warming was proposed. Furthermore, three scenarios of global warming were defined based on gas emissions, global population growth, introduction of new and clean technologies, and use of fossil sources of energy. It was found that the lifetime reduction induced by global warming was more significant for structures located in chloride-contaminated environments far from the sea. The results also indicated that the climate change effect was higher for structures located in oceanic environments and could lead to lifetime reductions ranging from $2 \%$ to $18 \%$. Hackl and Kohler [26] presented a generic framework for the stochastic modeling of reinforced concrete deterioration caused by corrosion. Their framework enabled the coupling of probabilistic models for the initiation and propagation of corrosion in service life models. In their framework, existing probabilistic models for chloride and carbonation initiation with models for the propagation and consequences of corrosion were coupled. To achieve the task, they combined structural reliability analysis with Bayesian networks in order to estimate the probability of failure of a reinforced concrete structure. In 2016, Pang and Li [27] carried out the filed investigations of seventeen highpile wharf structures located at the south coast of China. They compared the obtained results with the long-term exposure test results in terms of chloride ingress profile. The probability models for surface chloride content and chloride diffusion coefficient were derived accordingly. They also investigated the effects of different models of chloride ingress parameters, based on exposure trails or based on real structure surveys, on the expected service life of marine structures. It was found that the height-dependency of surface chloride indicated the existence of a "semisplash" zone, and the existence of semisplash zone and the addition of BFS in concrete have significant effects on the service life of concrete structures. Yang et al. [28] carried out design and optimization of the maintenance works of reinforced concrete (RC) elements in a long life-span marine port in Shanghai, China. In their study, the deterioration of RC elements was dominated by the reinforcement steel corrosion induced by external chloride penetration. The deterioration model was established for the RC elements with prescribed durability limit state, and the failure probability evolution was calculated through Monte Carlo simulations. Furthermore, the preventive, necessary, and mandatory maintenances corresponded, respectively, to probability levels of 2, 5, and 20\%, and also three schemes of maintenance planning were investigated: unsynchronized, synchronized, and coating-synchronized schemes. From their analysis, it was found that the coating-synchronized scheme achieved the optimal cost as well as delayed the deterioration rate of beam elements. In their study, they also assumed that with maintenances, the durability state of RC elements was assumed to be totally restored to its initial state. However, this assumption shows the limitation of their study. This is due to the fact that after concrete repairs, the influence of remaining chloride ions, which are used to indicate the durability in their study, should also be taken into account.

Although the aforementioned researchers studied the probabilistic service life of concrete structures without or with repairs, they did not consider multiple repairs accompanied with the interaction of chloride transport after concrete repairs. That kind of repairs is important, in particular, in the current situation at which many structures drastically deteriorate after operating for a period of time. Based on further literature reviews, there were researchers who studied such kind of repairs. For example, the study of Petcherdchoo [29] carried out probabilistic assessment of chloride ions in concrete with repairs. The study simplified the assessment by focusing on only two random variables, i.e., surface chloride and diffusion coefficient. However, there are two observations in that study. First, in real practice, not only the surface chloride and diffusion coefficient are random, but also threshold depth (cover depth) and critical chloride value do so. Second, that study defined critical time as the application repair time for preventing concrete cracking. However, in real practice, the time after concrete cracking to severe concrete deterioration is relatively short. If this kind of concrete cracking limit state is focused, it would be too risky for concrete structures. Hence, many researchers are interested in the time of corrosion initiation rather than concrete cracking. Due to these two observations, that study is limited. In 2014, Rahimi et al. [30] studied probabilistic approaches for modeling the residual service life of marine concrete structures after concrete repairs. However, their study has two restrictions. First, in 
their study, they considered three repair cases as follows. In the first case, the cover concrete was entirely removed and replaced with a repair material. And, the remaining layer of concrete behind the reinforcement was assumed unaffected by chloride ions. Hence, the design of the service life of a structure with regard to chloride-induced corrosion of the reinforcement was based on a common 1-layer system. In the second case, the cover concrete was only partially removed and replaced with a repair material. Moreover, the remaining layer of concrete in the cover and behind the reinforcement was assumed unaffected by chloride ions. In the third case, the concrete cover is only partially removed and replaced with repair material. And, the remaining layer of concrete contained residual chloride ions. Because the most important location in concrete structures is the position of reinforcement, it would be more appropriate to reduce the amount of chloride ions at the location of reinforcement (cover depth) rather than partial concrete cover. Hence, the second and third cases in their study are not sufficient. Although the first case considered the removal of the entire cover concrete, the remaining layer of concrete behind the reinforcement was assumed unaffected by chloride ions. Such kind of residual chloride ions is important, because they are near the location of the reinforcement. As a result, both removing at least the entire cover concrete and considering the effect of residual chloride ions are necessary. Second, they evaluated the residual service life of concrete structure after only one repair. However, multiple repairs for service life extension can occur over the lifetime of concrete structures. In order to bridge these gaps, this study aims at reporting probabilistic and sensitivity analysis of service life (time to concrete repairs) and associated parameters for attaining corrosion-free condition of chloride-attacked concrete structures. Moreover, concrete structures are multiply repaired at least up to concrete cover depth. Four groups of parameters are studied: (1) time-dependent chloride content, (2) mean and median of corrosion initiation and repair application times, (3) percent confidence of repairs, and (4) the total expected number of repairs. To achieve these, a computational approach and probabilistic data (surface chloride, diffusion coefficient, cover depth, and critical chloride) for chloride transport in concrete without and with multiple repairs are introduced for study. These are explained as follows.

\section{Computational Approach}

The computational approach in this study is an approach, which combines the Latin Hypercube technique with a Crank-Nicolson-based finite difference approach. The flowchart of the proposed approach is shown in Figure 1. It consists of two main shaded areas or loops. The internal loop represents the Crank-Nicolson-based finite difference approach for determining chloride transport in concrete without and with repairs by cover replacement, whereas the external loop represents the approach that uses the Latin Hypercube technique for sampling random numbers and feeding all random numbers into the internal loop. The models for chloride transport in concrete without

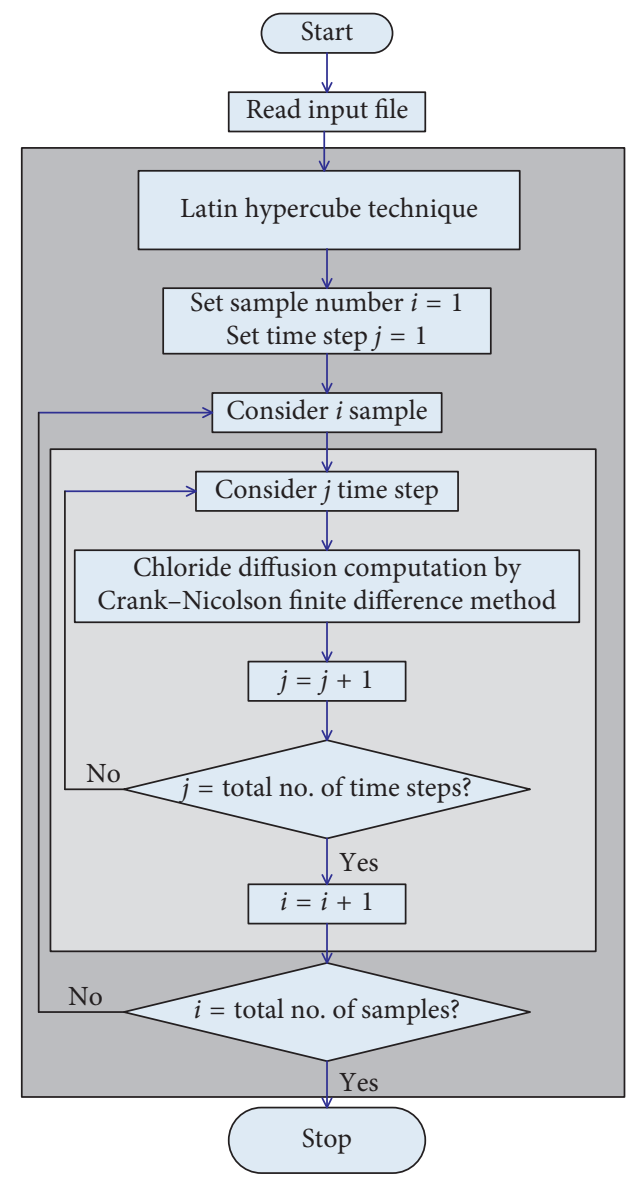

Figure 1: Flowchart for the developed program.

and with repairs using the Crank-Nicolson-based finite difference approach and the sampling method using the Latin Hypercube technique are explained as follows.

\subsection{Model of Chloride Transport in Concrete without Repairs.}

The one-dimensional partial differential equation (1-D PDE) for chloride diffusion in concrete structures $[21,31]$ can fundamentally be written as

$$
\frac{\partial C}{\partial t}=\frac{\partial}{\partial x} D \frac{\partial C}{\partial x},
$$

where $C$ is the chloride content as a function of position $x$ and time $t$ and $D$ is the chloride diffusion coefficient of concrete. If the initial condition (initial chloride content), boundary condition (surface chloride, $C_{S}$ ), and material property (chloride diffusion coefficient, $D$ ) are assumed to be zero, constant, and constant, respectively, a simple solution for Equation (1) can be derived as

$$
C(x, t)=C_{S}\left[1-\operatorname{erf}\left(\frac{x}{2 \sqrt{D t}}\right)\right],
$$

where $\operatorname{erf}(\cdot)$ is an error function. This equation can be used to predict the diffusion of chloride ions through concrete, if the surface chloride and diffusion coefficient are known. Several researchers proposed deterministic data to represent 
these two variables, such as those shown in literatures [22, 32-34].

\subsection{Model of Chloride Transport in Concrete with Repairs.} The flowchart for determining the transport of chloride ions as shown in the internal loop of Figure 1 can be used to determine the transport of chloride ions in concrete with repairs by cover concrete replacement. Whenever concrete repairs in terms of cover concrete replacement is applied, the solution such as that in Equation (2) is complex to obtain. To explain this difficulty, let us consider Figure 2(a). At time $t_{j}$, the repair action by cover concrete replacement is applied. Hence, the concrete with the cover (threshold) depth of $X_{c}$ is taken off, and a repair material (shown by shaded zone) is replaced for the taken-off concrete. The thickness of replaced concrete is called repair depth or $X_{\mathrm{p}}$, which is not necessary to be the same as the concrete cover depth $X_{\mathrm{c}}$. After that, there are three principle stages as shown in Figure 2(b). First, at time $t_{j}$, the chloride ions in the original (old) concrete are about to redistribute from the original concrete through the repair material due to differential chloride ions in old concrete and repair materials [35]. So, the problem will involve solving the $\mathrm{PDE}$ with nonlinear chloride ion profile, or $C\left(x, t_{j}\right)$.

Secondly, when the redistributing chloride ions penetrate from the original concrete to the repair material, the problem involving space-dependent diffusion coefficient, or $D(x)$, will be encountered due to the difference of the diffusion coefficient between the original concrete and the repair material. Mathematically, the PDE based on Fick's second law can be written as

$$
\frac{\partial C}{\partial t}=\frac{\partial}{\partial x} D(x) \frac{\partial C}{\partial x}
$$

Thirdly, at time $t_{j+2}$, the penetrating chloride ions from concrete surface merge with the redistributing chloride ions at the point $x_{\mathrm{m}}$ as shown in Figure 2(b). This causes the interaction between chloride ions in the old concrete and those in the repair material. Moreover, the problem in solving the PDE will be encountered. It will be even more complicated, if the number of repairs is more than one due to multiple repairs. In order to avoid all of these difficulties, a Crank-Nicolson-based numerical scheme [36] is used as

$$
\begin{aligned}
\frac{c_{i, j+1}-c_{i, j}}{\Delta t}= & \frac{1}{2}\left(\frac{\left\lfloor D_{i+1 / 2}\left(c_{i+1}-c_{i}\right)_{, j+1}-D_{i-1 / 2}\left(c_{i}-c_{i-1}\right)_{, j+1}\right\rfloor}{(\Delta x)^{2}}\right. \\
& \left.+\frac{\left\lfloor D_{i+1 / 2}\left(c_{i+1}-c_{i}\right)_{, j}-D_{i-1 / 2}\left(c_{i}-c_{i-1}\right)_{, j}\right\rfloor}{(\Delta x)^{2}}\right),
\end{aligned}
$$

where $c_{i, j}$ and $c_{i, j+1}$ are the chloride contents at a mesh point $i$ at time $j$ and $j+1$, respectively, and $D_{i+1 / 2}$ and $D_{i-1 / 2}$ are the diffusion coefficients at mesh point $i+1 / 2$ and $i-1 / 2$, respectively. Moreover, they are equal to $\left(D_{i}+D_{i+1}\right) / 2$ and $\left(D_{i-1}+D_{i}\right) / 2$, respectively. In this study, $\Delta t$ and $\Delta x$ are the incremental time step (1 week) and the mesh point size $(1 \mathrm{~mm})$, respectively. It is noted that there is another method called multispecies approach, which is based on the
Nernst-Planck equation. Truc et al. [37] stated that this approach described the diffusion and the ionic interaction between several chemical species and included both the physical and chemical phenomena in chloride ingress. However, this approach required the greater number of input data making it inappropriate in many situations, e.g., probabilistic study, in spite of its most complete modeling [38]. As a result, the multispecies approach is not used in this study.

To calculate the diffusion of chloride ions, Equation (4) must iteratively be solved over time. Whenever the amount of chloride ions at the threshold depth $\left(X_{c}\right)$ reaches a specific critical chloride value, the repair by cover concrete replacement is applied as shown in Figure 2. Hence, cover concrete is replaced over the repair depth $\left(X_{\mathrm{p}}\right)$, and the diffusion coefficient of cover concrete will be updated in computation, for instance, $\left(D_{X_{\mathrm{p}}}\right)_{0}$ is updated as $\left(D_{X_{\mathrm{p}}}\right)_{\text {rep }}$. It is noted that $\left(D_{X_{\mathrm{p}}}\right)_{0}$ and $\left(D_{X_{\mathrm{p}}}\right)_{\text {rep }}$ are defined as the diffusion coefficient of original concrete and repair material, respectively, at the repair depth $X_{\mathrm{p}}$.

2.3. Probabilistic Sampling Method. Most of researchers [24, 26, 28] generally used the Monte Carlo simulation technique as a sampling method in their probabilistic study due to its simplicity. However, this technique requires a large amount of random samples for satisfactory confidence level. If it is combined with the iterative computation that is unavoidable in numerical prediction of chloride transport in concrete with repairs, the computational time is a big issue. Hence, another sampling method which is more effective must be introduced.

The report in a study [39] stated that the Latin Hypercube sampling technique $[40,41]$ was able to reduce the number of random samples in computation to a certain amount with satisfactory confidence level. Hence, the Latin Hypercube sampling technique is used in this study. By combining the chloride diffusion computation by the Crank-Nicolson-based finite difference method with the Latin Hypercube technique, the computational approach is developed in this study according to the flowchart in Figure 1 .

\section{Probabilistic Data}

In probabilistic assessment, there can be two groups of uncertainties to be categorized, i.e., the uncertainty related to chloride diffusion and that related to assessing criteria. For the first group, two random variables can be considered, i.e., surface chloride and diffusion coefficient, for original concrete. The uncertainty in the surface chloride, which represents the degree of chloride attack, occurs due to different or random chloride environment. The uncertainty in diffusion coefficient, which represents the resistance of concrete to chloride diffusion, occurs due to different or random concrete material properties. Although concrete structures have the same mix design, their material properties are probably different due to different environment, quality control, etc. For the uncertainty related to the 


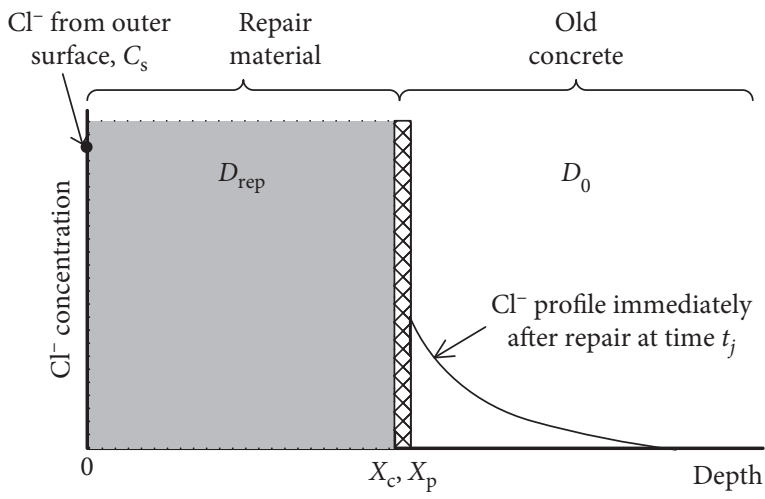

(a)

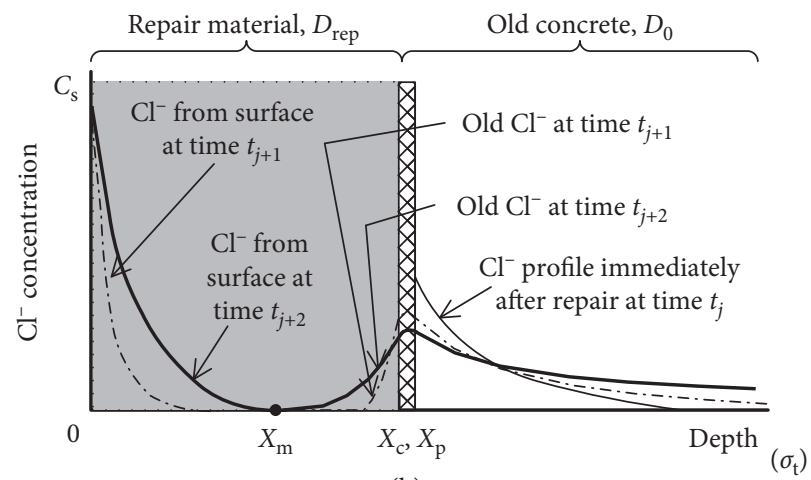

(b)

Figure 2: Chloride profiles after cover concrete replacement. (a) Immediately after repair. (b) After repair.

assessing criteria, two random variables can be considered, i.e., cover depth and critical chloride value. The uncertainty in the cover depth is related to quality control, while that in the critical chloride value can be considered due to random concrete material properties.

The study in the literature [42] both conducted tests and collected data for their study. Then, a set of probabilistic data for four governing random variables (surface chloride, diffusion coefficient, concrete cover depth, and critical chloride value) was proposed by considering the goodnessof-fit tests such as the Chi-square test, the KolmogorovSmirnov test, and the Cramer-Von Mises test. However, their data are found to be inappropriate for this study due to two reasons. First, the distribution type of some parameters is inappropriate. For example, the distribution type of the diffusion coefficient was proposed as the Weibull distribution. However, this kind of distribution type is not always bell-like, because it is highly sensitive to their descriptors, i.e., scale and shape factors. As a result, it is not appropriate to use the Weibull distribution in this study. In particular, the sensitivity study of random variables will be carried out. For the second reason, all the four random variables should be limited within a practical range. For example, the distribution type of the cover depth in their study was proposed as the normal distribution. However, it is impossible that the cover depth, which is directly related to the prediction of chloride diffusion through concrete without and with repairs, is negative. Although the probability of occurrence is low, the negative value of the cover depth might be obtained from numerical sampling. If this occurs, numerical computation cannot be completed. From these two reasons, the probabilistic assessment data in their study require revision.

Based on the raw data [42], a set of appropriate descriptors for the four random variables is proposed and compared with the raw data [42] as shown in Figure 3. In revising these data, both the goodness-of-fit tests and appropriateness of the descriptors are considered. Table 1 shows these proposed random variables: surface chloride $\left(C_{\mathrm{s}}\right)$, diffusion coefficient $\left(D_{\mathrm{o}}\right)$, concrete cover depth $\left(X_{\mathrm{c}}\right)$, and critical chloride $\left(C_{\text {Crit }}\right)$. It is noted that the dispersion of the cover depth in terms of standard deviation $(\sigma)$ is highest, while that in terms of coefficient of variation $(\mathrm{COV})$ is lowest.

\section{Proposed Repair Strategies for Corrosion- Free Condition}

In this study, it is assumed that the amount of oxygen and moisture is much enough to cause reinforcement corrosion, whenever the chloride content at the threshold depth (or concrete cover depth) reaches the critical chloride value. The time at which the critical value is reached is defined as the service life of concrete structures or the time of repair applications. In addition, it can be predicted by using the proposed approach explained in Section 2. Six repair strategies for corrosion-free condition are proposed as shown in Table 2 and applied at the time of repair applications. The diffusion coefficient is chosen as $D_{\mathrm{o}}, 0.75 D_{\mathrm{o}}$, or $0.5 D_{\mathrm{o}}$, while the depth of repairs is chosen as equal to the cover depth $\left(X_{\mathrm{c}}\right)$, $X_{\mathrm{c}}+35$, or $X_{\mathrm{c}}+50 \mathrm{~mm}$. For the abbreviation in Table 2, for example, $S 4$ means the repair strategy number 4 , and 75DC35 means that the diffusion coefficient of the repair material and the depth of repairs are equal to $0.75 D_{\mathrm{o}}$ and $X_{\mathrm{c}}+35 \mathrm{~mm}$, respectively. In addition, the design time period for corrosionfree condition is chosen as equal to 100 years.

\section{Numerical Assessment}

This study represents two main kinds of numerical assessment: deterministic and probabilistic. The deterministic assessment is to show the behaviors of chloride diffusion through concrete structures with multiple repairs. The probabilistic assessment consists of three parts: the assessment with 5 samples, that with 2000 samples, and the sensitivity analysis. The first part is to show how to assess the probabilistic chloride diffusion in concrete with repairs. The second and third ones are to perform the probabilistic and sensitivity analysis, respectively.

5.1. Deterministic Assessment. The surface chloride, the diffusion coefficient of original concrete, the cover depth, and the critical chloride are chosen as their mean value shown in the third column of Table 1. Moreover, six repair strategies in Table 2 are considered for comparison. It is noted that if, for example, the repair strategy of S6 is studied, 


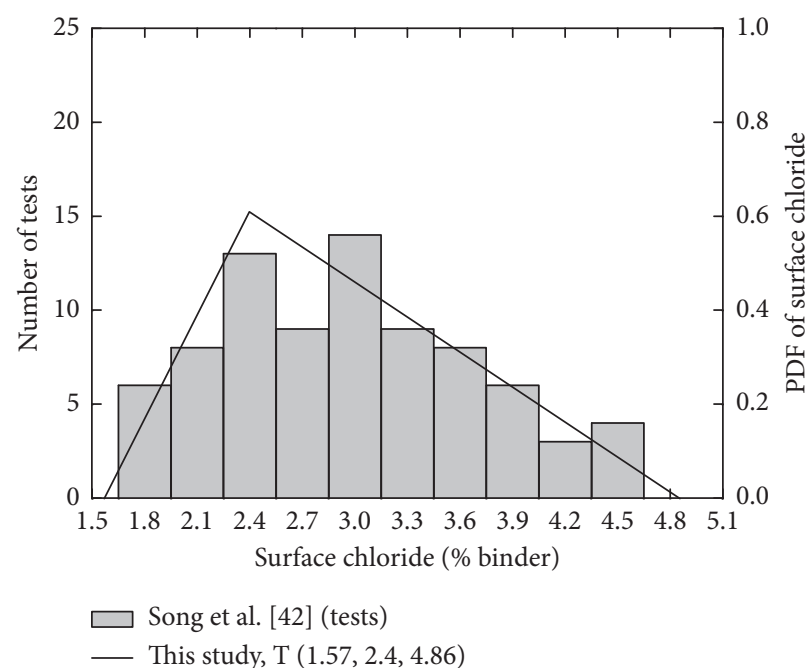

(a)

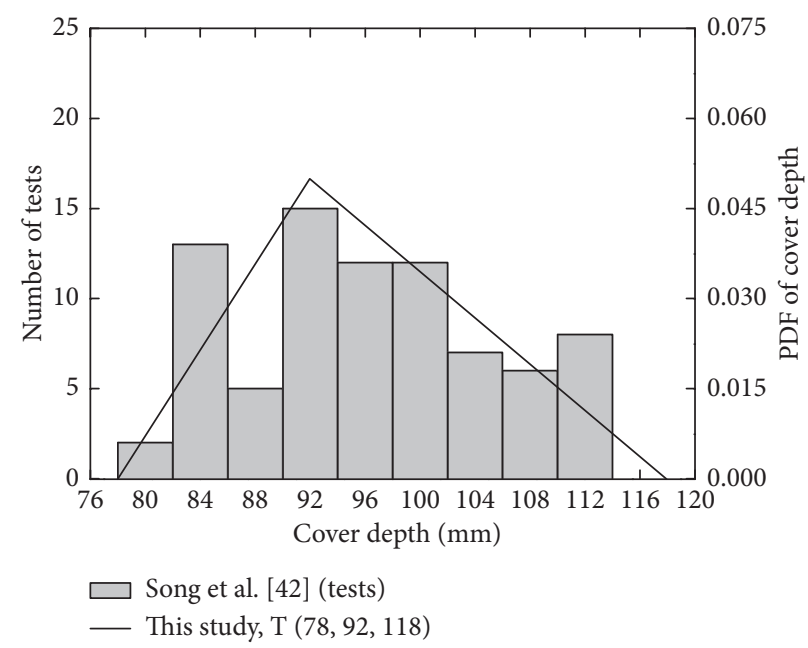

(c)

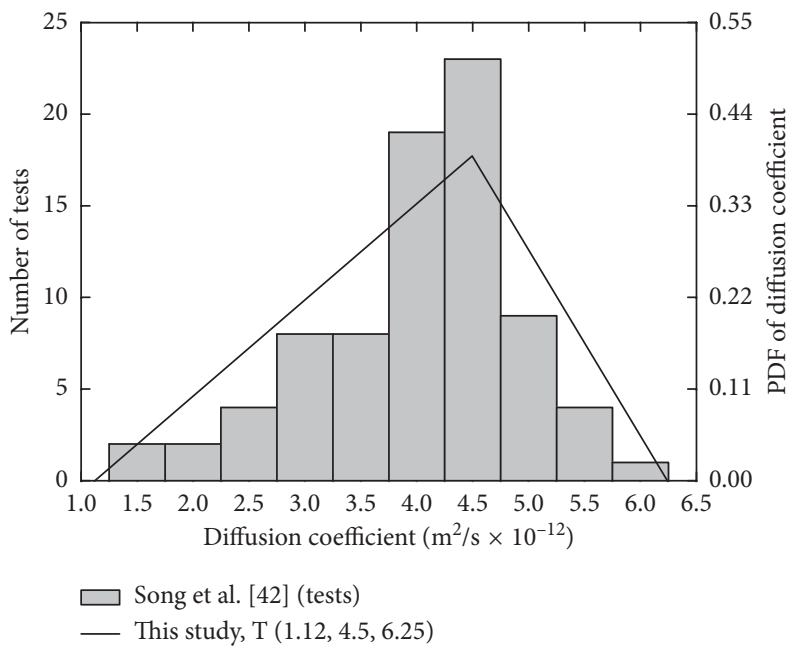

(b)

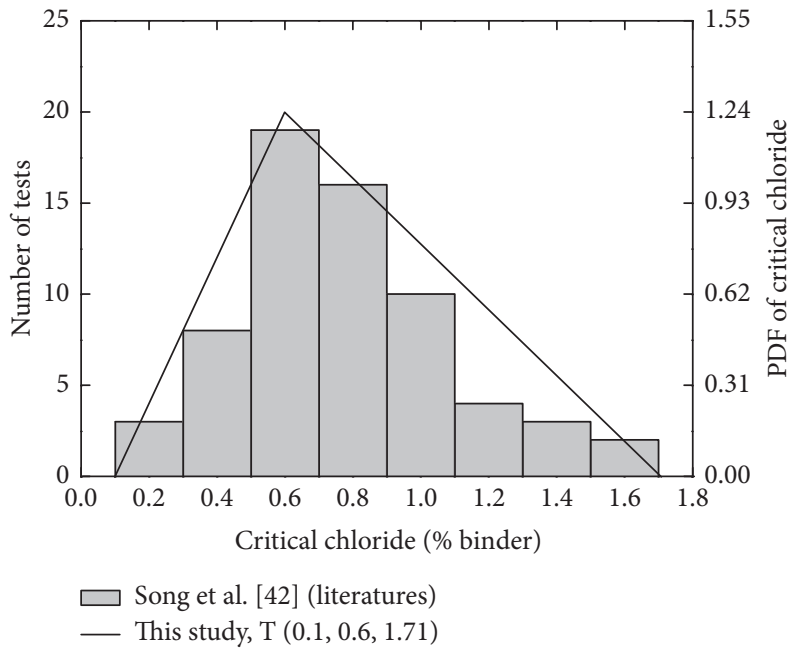

(d)

Figure 3: Raw data and proposed descriptors. (a) Surface chloride. (b) Diffusion coefficient. (c) Cover depth. (d) Critical chloride.

TABle 1: Proposed descriptors for four random variables.

\begin{tabular}{lcccc}
\hline Random variables & Descriptors & Mean $(\mu)$ & Standard deviation $(\sigma)$ & Coefficient of variation $(C O V)$ \\
\hline$C_{\mathrm{s}}(\%$ binder $)$ & $\mathrm{T}(1.57,2.4,4.86)$ & 2.94 & 0.7 & 0.24 \\
$D_{\mathrm{o}}\left(\times 10^{-12} \mathrm{~m}^{2} / \mathrm{s}\right)$ & $\mathrm{T}(1.12,4.5,6.25)$ & 3.96 & 1.06 & 0.27 \\
$X_{\mathrm{c}}(\mathrm{mm})$ & $\mathrm{T}(78,92,118)$ & 96 & 8.29 & 0.087 \\
$C_{\text {Crit }}(\%$ binder $)$ & $\mathrm{T}(0.1,0.6,1.71)$ & 0.8 & 0.34 & 0.42 \\
\hline
\end{tabular}

$\mathrm{T}(a, b, c)$ means triangular distribution with minimum, mode, and maximum of $a, b$, and $c$, respectively.

TABLE 2: Six proposed repair strategies for corrosion-free condition.

\begin{tabular}{|c|c|c|c|}
\hline Code of repairs & Repair application time & Diffusion coefficient of repair material, $D_{\text {rep }}$ & Depth of repairs, $X_{\mathrm{p}}$ \\
\hline S1: DC & & $D_{\mathrm{o}}$ & Cover \\
\hline S2: DC35 & & $D_{\mathrm{o}}$ & Cover $+35 \mathrm{~mm}$ \\
\hline S3: 75DC & & $0.75 D_{\mathrm{o}}$ & Cover \\
\hline S4: 75DC35 & Whenever $\mathrm{Cl}_{\mathrm{TH}, \mathrm{T}}=\mathrm{C}_{\text {Crit }}$ & $0.75 D_{\mathrm{o}}$ & Cover $+35 \mathrm{~mm}$ \\
\hline S5: 75DC50 & & $0.75 D_{\mathrm{o}}$ & Cover $+50 \mathrm{~mm}$ \\
\hline S6: 50DC50 & & $0.5 D_{\mathrm{o}}$ & Cover $+50 \mathrm{~mm}$ \\
\hline
\end{tabular}

$\mathrm{Cl}_{\mathrm{TH}, \mathrm{T}}$ means chloride content at the threshold depth $\mathrm{TH}$ and time T. $C_{\text {Crit }}$ means critical chloride. 
the diffusion coefficient of the repair material and the repair depth are equal to $1.98 \times 10^{-12} \mathrm{~m}^{2} / \mathrm{s}\left(0.5 D_{\mathrm{o}}\right)$ and $146 \mathrm{~mm}$ $(96+50)$, respectively.

The chloride diffusion through the depth of a concrete structure with S1 and S6 is shown in form of space-dependent chloride profiles in Figures 4(a)-4(d). From Figure 4(a), the chloride ions continuously penetrate through the original concrete. In year 30 (about 31 weeks after the year 30), the chloride profile reaches the critical value at the threshold depth (cover depth) as shown by the profile at year 30B ("B" means Before repair). If the repair strategy $\mathrm{S} 1$ is selected, the concrete cover over $96 \mathrm{~mm}$ is replaced by the repair material having the diffusion coefficient of $3.96 \times 10^{-12} \mathrm{~m}^{2} / \mathrm{s}$ as shown by the shaded zone in Figure 4(b). Immediately after the repair, the chloride profile becomes the profile at year 30A ("A" means After repair). At year 31, the chloride ions from the surface of concrete penetrate through the cover concrete, and the remaining chloride ions in the original concrete (near the threshold depth) will both redistribute through the repair material and distribute further through the original concrete. After that, the chloride ions will continuously penetrate through the concrete as shown.

But if S6 is selected instead, the concrete cover over $146 \mathrm{~mm}$ is replaced by the repair material having the diffusion coefficient of $1.98 \times 10^{-12} \mathrm{~m}^{2} / \mathrm{s}$ as shown by the shaded zone in Figure 4(d). The behaviors of chloride ion penetration near the surface and the threshold depth of concrete with S6 are identical with those with S1, except that the chloride profiles are not exactly the same. By comparing the chloride profiles at years 31 to 45 between Figures 4(b) and 4(d), there are two observations. First, the chloride penetration from the surface of concrete with S6 in Figure 4(d) is slower than that with S1 in Figure 4(b), because of lower diffusion coefficient (better quality) of the repair material of S6. Second, the chloride redistribution from the original concrete to the threshold depth of concrete with S6 is slower than that with S1, because of deeper repair depth of S6.

The comparison of time-dependent chloride profiles without and with repair by S1 and S6 is shown in Figure 5. Without repair, the chloride content at the cover depth of $96 \mathrm{~mm}$ will continuously increase causing possible corrosion of reinforcement in the concrete structure. If the time which the chloride profile reaches the critical value of $0.8 \%$ binder (mean value of $C_{\text {Crit }}$ in Table 1) is defined as the service life of concrete structures or the time to repair, the time to the first repair is approximately equal to 30 years. If the repair strategy of S1 is applied in the year 30, the chloride content at the reinforcement will be controlled below the critical value. Immediately after the repair, the time-dependent chloride content at the reinforcement as shown in Figure 5 decreases to zero due to removing the chloride ions with the taken-off concrete (see also the chloride profile in the year $30 \mathrm{~A}$ in Figure 4(b)). However, the chloride content suddenly increases, because of immediate redistribution of chloride ions from the original concrete (see also the chloride profile in the year 31 in Figure 4(b)). This immediate redistribution of chloride ions occurs, because the microstructure of the fresh repair material is not dense yet, leading to a very low chloride diffusion resistance of repair material [43]. By the effect of the first repair, the time which the chloride profile crosses the critical value to start reinforcement corrosion will be prolonged. After the first repair, the chloride profile reaches the critical value two more times within the design time period of 100 years, and the same kind of concrete repair as S1 is reapplied as shown in Figure 5.

But instead, if the repair strategy of S6 is applied in the year 30, the behavior of chloride penetration is different from applying S1. Immediately after the repair by S6, the chloride content decreases to zero, and then gradually increases. This gradual increase compared to S1 occurs because of two reasons: longer distance of chloride redistribution from the original concrete to the threshold depth (Figures 4(b) and $4(\mathrm{~d})$ ), and lower diffusion coefficient of the repair material (Table 2). The effect of the first repair by S6 lasts until year 90, and then, the second repair is applied. After that, the chloride profile will never reach the critical value any more within 100 years. In comparison between S1 and S6, the number of repairs is equal to thrice and once, respectively. Hence, better repair material and deeper repair depth by S6 lead to fewer numbers of repairs within the design time period.

In comparison among six repair strategies, the repair application time and the number of repairs can be calculated as shown in Table 3. Within the design time period of 100 years, the concrete structure with S1 and S2 requires three repairs, while that with $S 3$ to $S 6$ requires two repairs. This implies that lower diffusion coefficient (better quality) of repair materials in S3 to S6 is more effective due to lower number of repairs.

\subsection{Probabilistic Assessment}

5.2.1. With 5 Samples. From the Latin Hypercube sampling technique, five simulations for random numbers of four random variables are generated as shown in Table 4. It is noted that the original values of the cover depth $X_{\mathrm{c}}$ in the simulation numbers 1 and 2 are randomly generated as 99.4332 and 87.883 , respectively. However, they are rounded as 99 and $88 \mathrm{~mm}$ in order to be consistent with the unit of the mesh point size, which are in millimeters as mentioned in Section 2.2.

If the repair strategy of $\mathrm{S6}$ is selected, the time-dependent chloride profiles can be calculated as shown in Figure 6. There are six profiles, i.e., five sample profiles and the mean of the five samples profiles. The five sample profiles can be separated into two groups: three with need of repairs and the other two with no need of repairs. The chloride content of the three profiles with need of repairs increases up to their own critical value (see also Table 4) and decrease to zero due to repairs, while that with no need of repairs will continuously increase (see the two hidden lines). It is noted that the two profiles have no need of repair, because they are always below their own critical value. Although one of them crosses the mean of the critical chloride, a repair is still not applied. The mean profile at time $t$ can be computed based on the five sample profiles as

$$
\mu_{t}=\frac{\sum_{i=1}^{n} c_{i, t}}{n}
$$




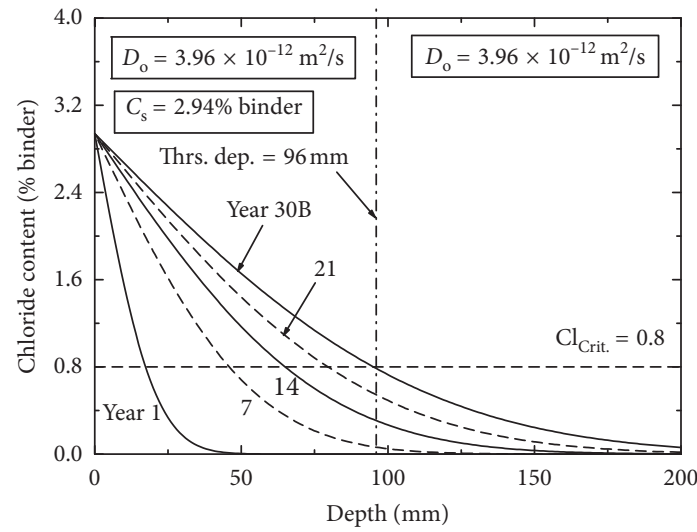

(a)

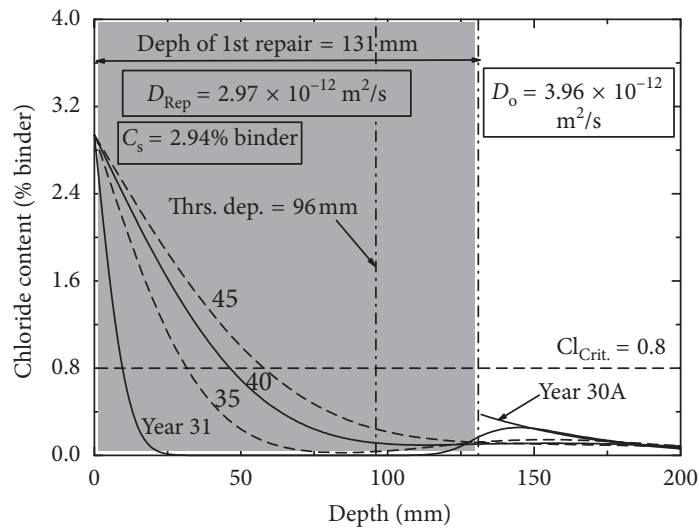

(c)

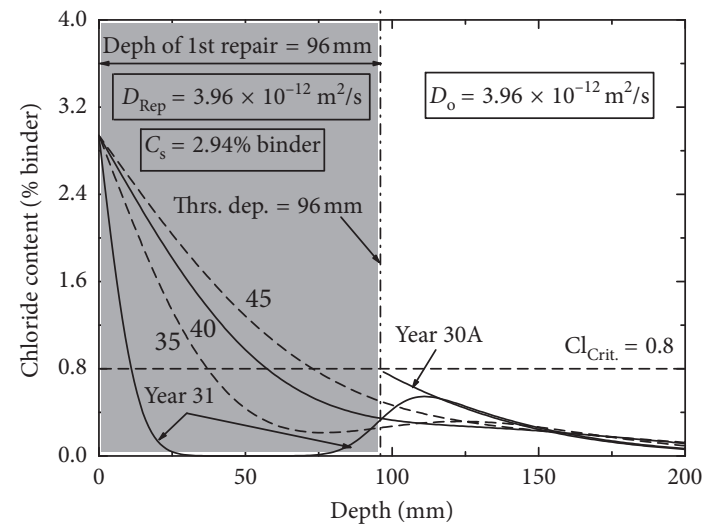

(b)

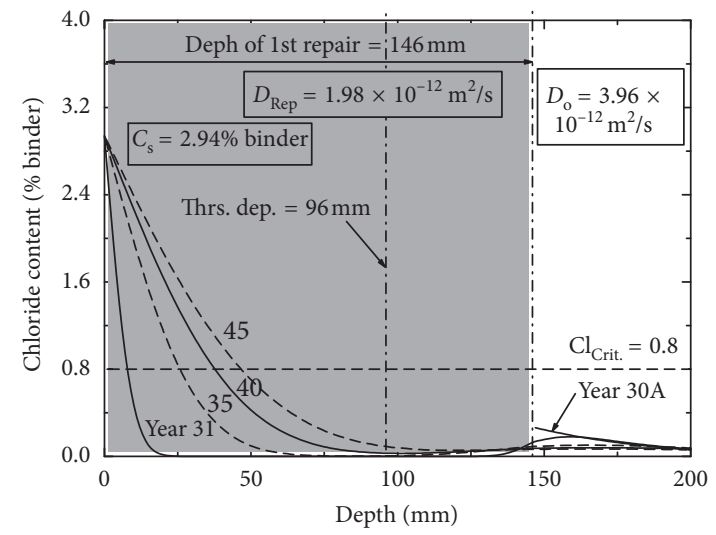

(d)

Figure 4: Deterministic space-dependent chloride profiles with S1, S4, and S6. (a) Year 1 to year 30B. (b) Year 30A to year 45 (with S1). (c) Year 30A to year 45 (with S4). (d) Year 30A to year 45 (with S6).

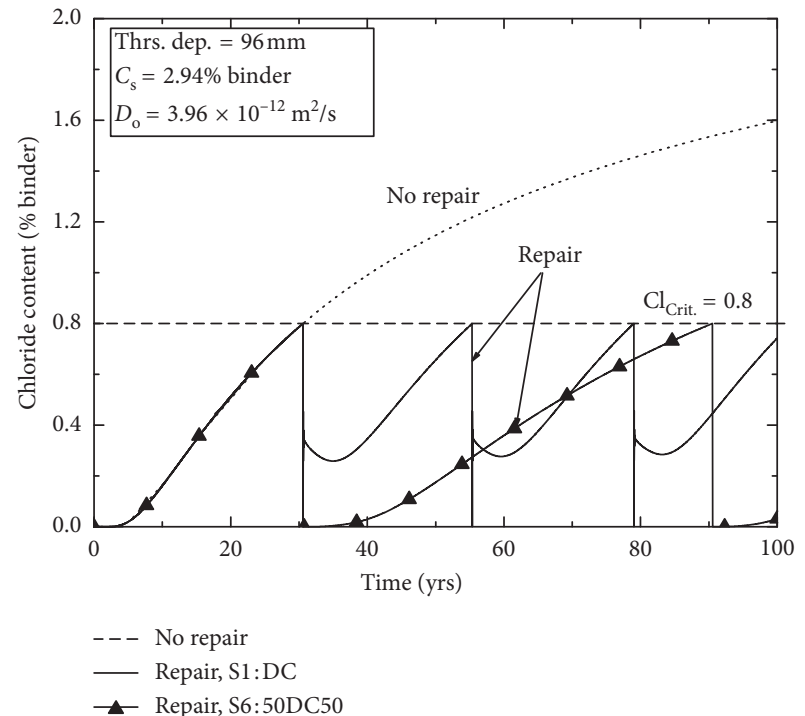

Figure 5: Deterministic time-dependent chloride profiles without and with S1 and S6.

where $c_{i, t}$ is the chloride content of the $i$-th sample at time $t$ and $n$ is the total number of samples. It is noted that the mean profile (the darkest line) never reaches the mean of
TABle 3: Number of repairs and repair application time for six strategies by deterministic assessment.

\begin{tabular}{lccccc}
\hline \multirow{2}{*}{ Strategy } & \multicolumn{6}{c}{ Repair application time, yrs. } & \multirow{2}{*}{ Number of repairs } \\
& First & Second & Third & Fourth & \\
\hline S1 & 30.6 & 55.4 & 79 & $>100$ & 3 \\
S2 & 30.6 & 60.6 & 90.5 & $>100$ & 3 \\
S3 & 30.6 & 66.8 & $>100$ & $>100$ & 2 \\
S4 & 30.6 & 69.4 & $>100$ & $>100$ & 2 \\
S5 & 30.6 & 71.2 & $>100$ & $>100$ & 2 \\
S6 & 30.6 & 90.5 & $>100$ & $>100$ & 2 \\
\hline
\end{tabular}

the critical value nor decreases to zero, because it is the average value which falls within the range of the five sample profiles.

5.2.2. With 2000 Samples. In this part, all random variables, i.e., surface chloride, diffusion coefficient, concrete cover depth, and critical chloride, from Table 1 are used for study. For repairs, concrete structures with six repair strategies in Table 2 will be compared. By using these data in the proposed computational approach, observations can be drawn as follows.

In case of no repair, Figure 7 shows the comparison of two kinds of assessment: deterministic and probabilistic. For 
TABLE 4: Five generated random numbers for concrete structures with S6.

\begin{tabular}{lcccccc}
\hline Simulation & \multicolumn{4}{c}{ Random variables } & \multicolumn{2}{c}{ S6: 50DC50 } \\
number & $C_{\mathrm{s}}$ & $D_{\mathrm{o}}$ & $X_{\mathrm{c}}$ & $C_{\text {Crit }}$ & $D_{\text {rep }}=0.5 D_{\mathrm{o}}$ & $X_{\mathrm{p}}=X_{\mathrm{c}}+50$ \\
\hline 1 & 3.15 & 3.83 & 99 & 1.32 & 1.915 & 149 \\
2 & 4.29 & 2.24 & 88 & 0.82 & 1.12 & 138 \\
3 & 1.82 & 4.57 & 103 & 1.17 & 2.285 & 153 \\
4 & 2.99 & 2.94 & 79 & 0.62 & 1.47 & 129 \\
5 & 2.28 & 1.87 & 112 & 1.02 & 0.935 & 162 \\
\hline
\end{tabular}

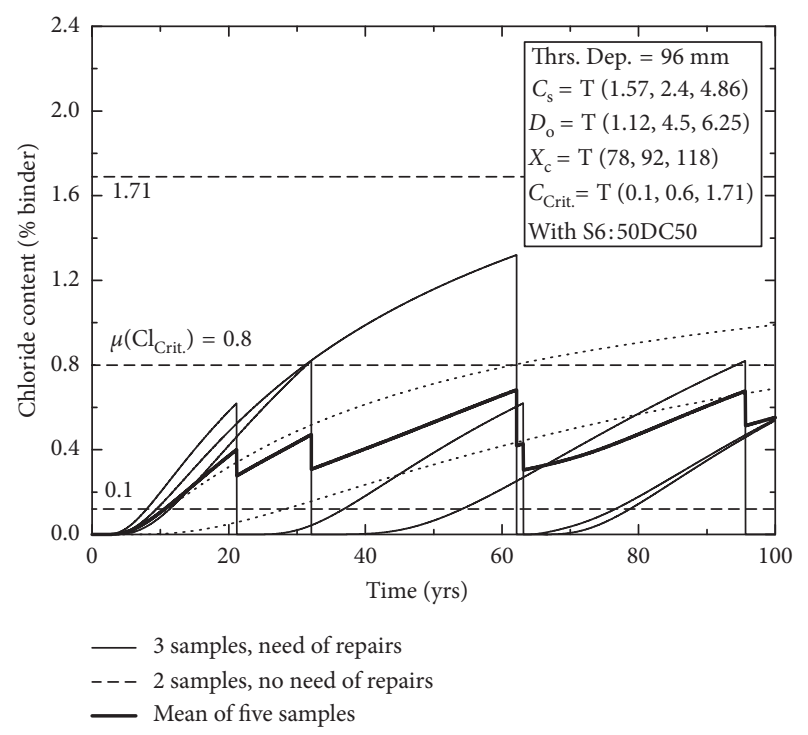

Figure 6: Probabilistic time-dependent chloride profiles based on five sets of random samples.

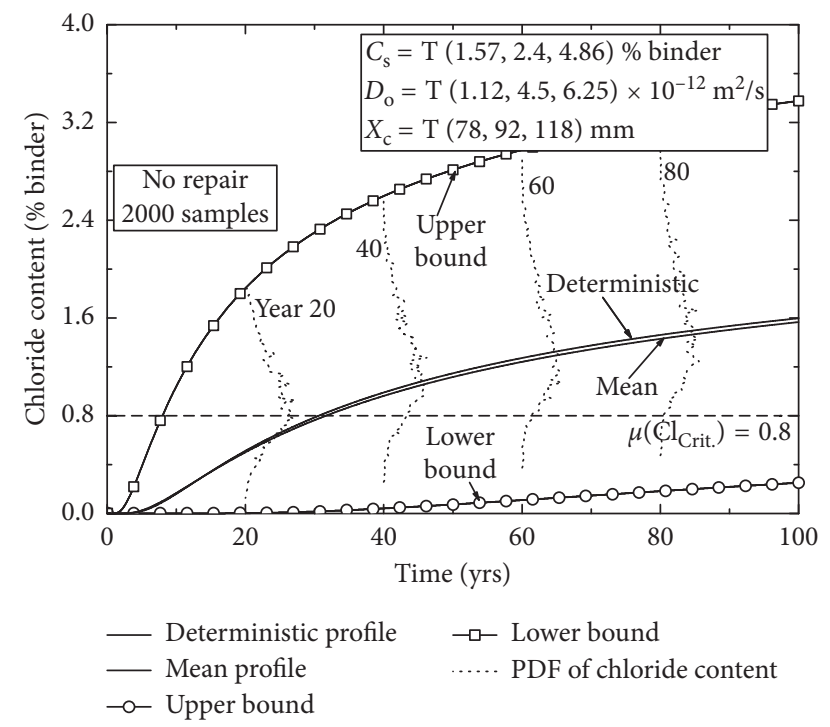

Figure 7: Deterministic and mean profiles, upper and lower bound, and PDF of chloride content.

the deterministic assessment, the chloride profile as well as the lower and upper bounds of chloride content is shown. For these profiles, the surface chloride, the diffusion coefficient of original concrete, and the cover depth are chosen as equal to their mean value, as well as equal to their upper and lower limits as shown in Table 5. For the probabilistic assessment, the mean profile and the yearly probability density functions (PDFs) of chloride content are shown. From comparison, the deterministic profile is slightly different from the mean profile. This difference occurs, because all the randomly generated values of the cover depth in the probabilistic assessment are always rounded as integers in order to be consistent with the mesh point size (see $X_{\mathrm{c}}$ in Table 4). It is also observed that at the years of 20, 40,60, and 80, the PDF falls within the upper and lower bounds. In addition, from the PDF, the dispersion of chloride content increases with time.

Other than the PDF of chloride content, the dispersion of the chloride content can be shown in terms of the standard deviation $\left(\sigma_{t}\right)$ and the coefficient of variation $\left(\mathrm{COV}_{t}\right)$, respectively, by using the following equations:

$$
\begin{aligned}
\sigma_{t} & =\sqrt{\left(\frac{\sum_{i=1}^{n} c_{i, t}^{2}}{n}\right)-\mu_{t}^{2}}, \\
\operatorname{COV}_{t} & =\frac{\sigma_{t}}{\mu_{t}} .
\end{aligned}
$$

The time-dependent profiles of the mean, the standard deviation, and the coefficient of variation of chloride content for concrete structures without and with the repair strategy of S1 can be compared in Figure 8. It can be seen that the mean profile for concrete with S1 is lower than that without, because the chloride content of all samples for concrete with S1 is limited below its critical chloride value due to repairs. Moreover, the dispersion in terms of the standard deviation is also lower, but that in terms of the coefficient of variation $(\mathrm{COV})$ is higher. In fact, if two random variables, i.e., both $D_{\text {rep }}$ and $X_{\mathrm{p}}$, are combined in consideration due to applying S1, the dispersion must theoretically increase. The increase occurs, because the uncertainty of the two random variables is combined. This observation agrees with the dispersion in terms of the coefficient of variation (COV). As a result, the dispersion should be calculated in terms of the coefficient of variation rather $(\mathrm{COV})$ than the standard deviation.

The probabilistic time to repairs can be represented in terms of the PDF (probability density function) and CDF (cumulative distribution function) of repair application time. From computation, Figures 9(a) and 9(b) show the PDF and CDF, respectively, for concrete structures with S1. There are two approaches to define the time to repairs, i.e., (1) mean and standard deviation and (2) median (or 50percentile). From the PDF in Figure 9(a), the mean and the standard deviation of the first application time for S1 can be calculated as equal to 34 and 20.1 years, respectively. Both values are calculated based on the $92.4 \%$ confidence which is shown at the year 100 of the CDF of repair application time in Figure 9(b) (0.924). This implies that $7.6 \%$ of the total number of concrete structures do not need any repair within the design time period of 100 years. If more percent confidence is needed, the design time period must be longer so that the CDF of repair application time can be completely 
TABle 5: Parameters for deterministic assessment.

\begin{tabular}{lccc}
\hline Analysis type & $C_{\mathrm{s}}(\%$ binder $)$ & $D_{\mathrm{o}}\left(\mathrm{m}^{2} / \mathrm{s}\right)$ & $X_{\mathrm{c}}(\mathrm{mm})$ \\
\hline Deterministic profile & 2.94 & $3.96 \times 10^{-12}$ & 96 \\
Upper bound & 4.86 & $6.25 \times 10^{-12}$ & 78 \\
Lower bound & 1.57 & $1.12 \times 10^{-12}$ & 118 \\
\hline
\end{tabular}

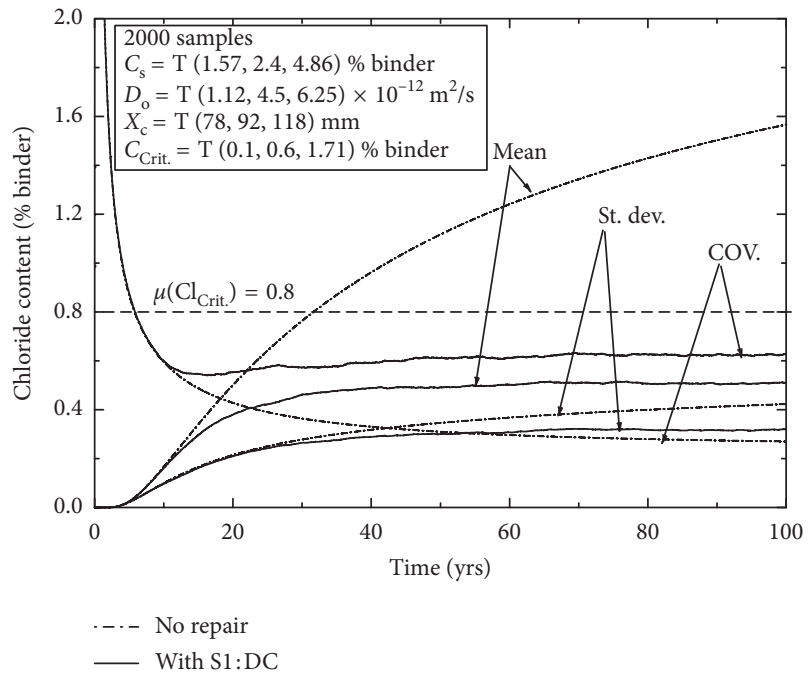

Figure 8: Probabilistic time-dependent chloride profiles without and with S1.

captured. Moreover, if the design time period is longer, the mean and standard deviation will be slightly different. From Figures 9(a) and 9(b), the mean, the standard deviation, and the percent confidence for the second, third, and fourth applications can be tabulated in Table 6. It is noted that if the design time period is longer, those means and standard deviations will be considerably changed. In particular, those of the fourth application will be most changed due to its lowest percent confidence. This shows that the mean and standard deviation of repair application time are sensitive to the design time period.

By further considering Figure 9(b), the CDF of repair application time can be referred to the probability of repair applications at any year. For example, there is $50 \%$ probability of the first repair application time (0.5) at year 30.7. Moreover, there is a $25 \%$ probability of the first repair application time at year 19.2. This indicates the probability of reinforcement corrosion initiation. If there are, for example, 2000 concrete structures exposed to chloride environment, 500 (or 25\%) of them are expected to have reinforcement corrosion. Therefore, repair planning is recommended for them. However, the deterministic assessment in Figure 5 shows that the corrosion does not occur prior to or even in year 29 , and no repair is required. Hence, if only the deterministic assessment using the mean of random variables as shown in Figure 5 is considered, the expected corrosion cannot be predicted. This reveals that repair planning by the deterministic assessment is not enough.

In terms of the median of repair application time, the time to repairs is defined as the time which $50 \%$ of the total number of concrete structures starts to have reinforcement corrosion and requires a repair for corrosion-free condition. From the CDF of repair application time in Figure 9(b), the median of the first, second, and third repairs of S1 can be tabulated in Table 6 . They are approximately equal to 30.7 (Figure 9), 55.4, and 79. In comparison, the deterministic repair time as shown in Table 3 is equal to 30.6, 55.4, and 79, respectively. This reveals that the deterministic repair times are closer to their median than the aforementioned mean (Tables 3 and 6). This occurs, because the design time period is not long enough to represent their mean with high percent confidence. If the design time period is longer, the percent confidence will be higher and the mean of repair application time will be closer to their median.

From Figure 9(b), the probability of the first, second, and third repair applications at year 50 is approximately equal to $75.5 \%, 45.7 \%$, and $23.7 \%$, respectively. Moreover, that at year 100 is approximately equal to $92.4 \%, 80.2 \%$, and $63.6 \%$, respectively. Based on these three repairs, the total expected number of repair applications at years 50 and 100 can be calculated as equal to 1.45 (a combination of $75.5 \%, 45.7 \%$, and $23.7 \%$ ) and 2.36 (a combination of $92.4 \%, 80.2 \%$, and $63.6 \%)$, respectively. But if eight repairs are considered, the total expected number of repair applications at years 50 and 100 is approximately equal to 1.63 and 3.77 , respectively. In comparison, at year 50 , the consideration of the total expected number of repair applications for three repairs is not much different from that for eight repairs (1.45 to 1.63). However, at year 100 , it is quite different (2.36 to 3.77 ). As a result, if the design time period is longer, more number of repair applications should be included in calculating the total expected number of repair applications. Otherwise, it will be miscalculated.

The mean profiles of chloride content of concrete structures with six proposed repair strategies are compared in Figure 10. According to the effect of repairs, the six profiles can be separated into two groups: S1 and S3 and S2 and S4 to S6. There are two further observations. First, if S1 to $S 4$ are compared, it can be observed that the depth of repairs is more effective in reducing the mean profiles than the quality of repair materials (see also Table 2). Second, if S4 to S6 are compared, it seems that both the depth of repairs and the quality of repair materials do not obviously influence the mean profiles. These two observations show that deeper depth of repairs is not always better, because it has a limitation on reducing the amount of chloride ions. For more explanation, let compare Figures 4(c)-4(d). At year 30A in Figures 4(c) and 4(d), the amount of remaining chloride ions at the repair depth of 131 and $146 \mathrm{~mm}$, respectively, are sufficiently low. However, the $131 \mathrm{~mm}$ repair depth in Figure 4(c) is found to be deep enough to reduce the chloride ions redistributing to the cover depth. Hence, too deep repair, such as the $146 \mathrm{~mm}$ repair depth in Figure 4(d), is not recommended. On the other hand, the repair depth also depends on the immediate amount of chloride ions redistributing to the cover depth. It is noted that, in real practice, other factors, such as the cost of repairs and etc., are also found to control the repair strategy.

Although the mean profiles in Figure 10 can be used for comparing concrete structures with repairs, it is difficult to 


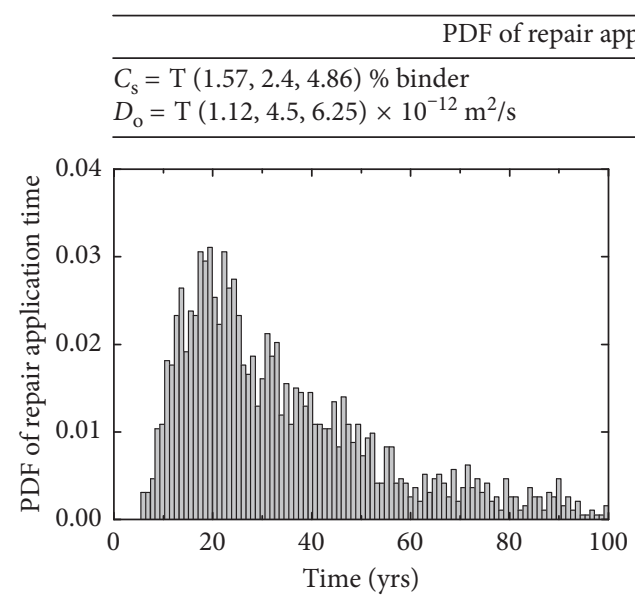

First application time

$($ mean, st. dev. $)=(34,20.1)$

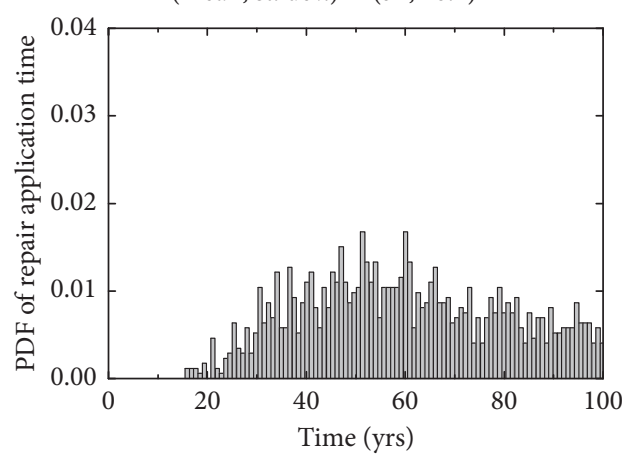

Third application time

$($ mean, st. dev. $)=(59.7,20.3)$
$X_{c}=\mathrm{T}(78,92,118) \mathrm{mm}$

$C_{\text {Crit. }}=\mathrm{T}(0.1,0.6,1.71) \%$ binder

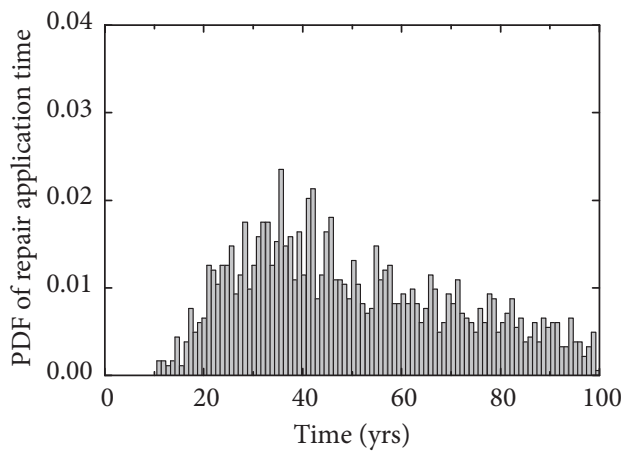

Second application time

$($ mean, st. dev. $)=(50.2,21.5)$

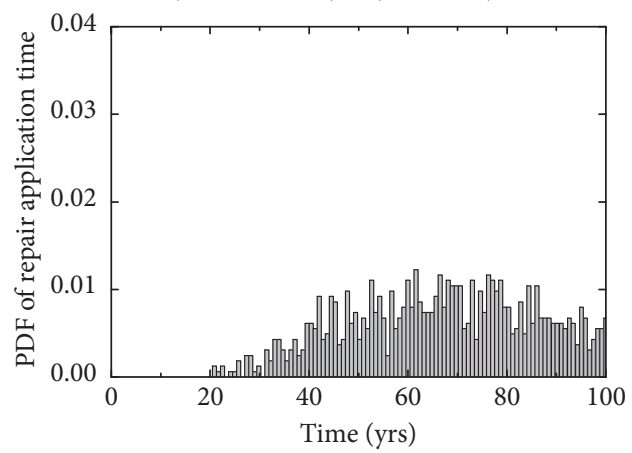

Fourth application time

(mean, st. dev. $)=(66.6,18.6)$

(a)

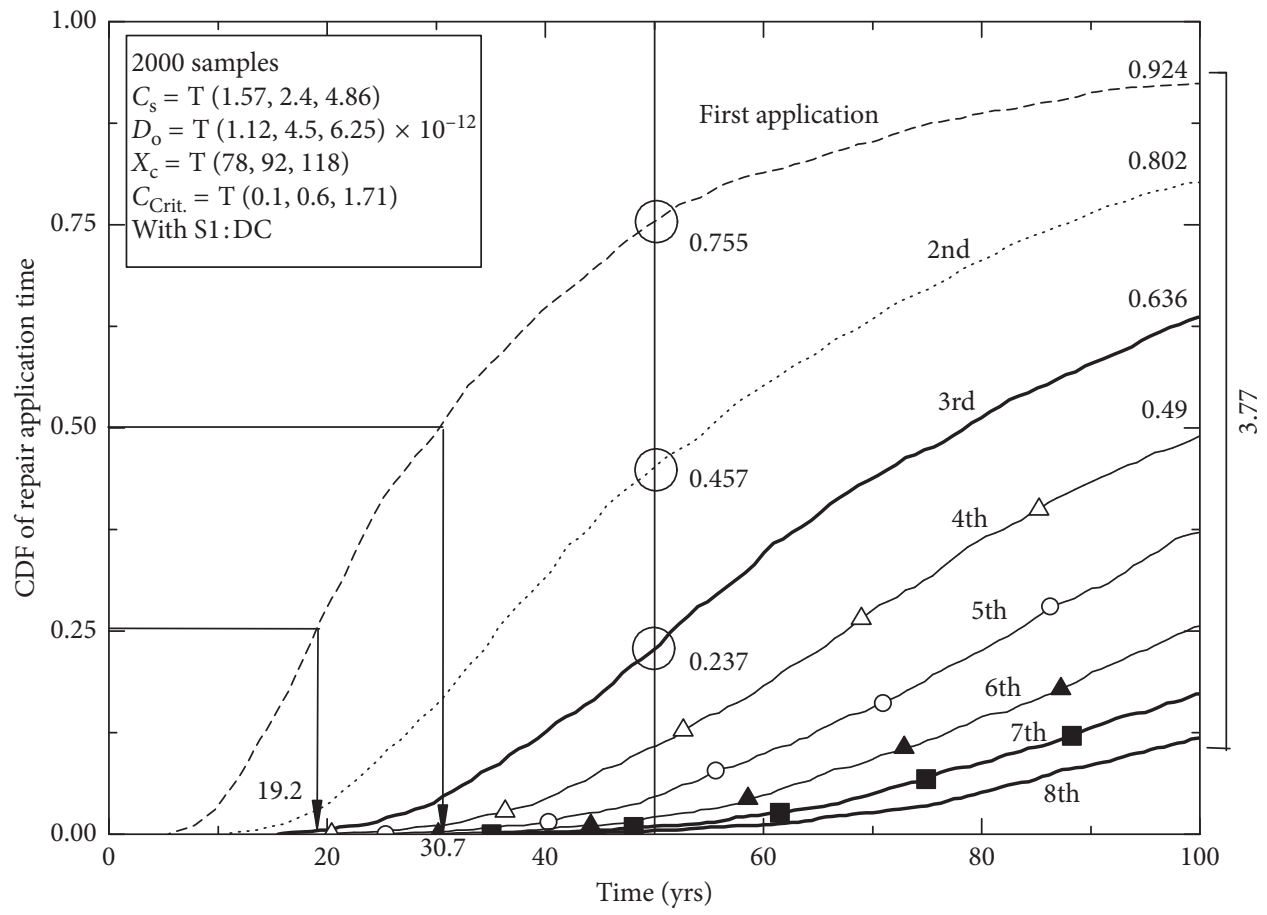

(b)

FIgURE 9: PDF and CDF of repair application time for S1. (a) PDF of repair application time. (b) CDF of repair application time. 
TABLE 6: Comparison of six repair strategies from probabilistic assessment.

\begin{tabular}{|c|c|c|c|c|c|c|c|c|c|}
\hline \multirow{2}{*}{ Strategy } & \multicolumn{4}{|c|}{ Mean of repair application time, yrs (\% confidence). } & \multicolumn{4}{|c|}{ Median of repair application time, yrs. } & \multirow{2}{*}{ No. of repairs } \\
\hline & First & Second & Third & Fourth & First & Second & Third & Fourth & \\
\hline S1 & $34(92.4)$ & $50.2(80.2)$ & $59.7(63.6)$ & $66.6(49)$ & 30.7 & 55.4 & 79 & $>100$ & 3.77 \\
\hline S2 & $34(92.4)$ & $51.5(77.1)$ & $61.7(58.2)$ & $68.5(41.7)$ & 30.7 & 59.1 & 87 & $>100$ & 3.37 \\
\hline S3 & $34(92.4)$ & $55.2(72.6)$ & $65(49.6)$ & $72.7(33.9)$ & 30.7 & 67.4 & $>100$ & $>100$ & 2.92 \\
\hline S4 & $34(92.4)$ & $55.3(69.7)$ & $67(46.7)$ & $73.9(28.4)$ & 30.7 & 68.8 & $>100$ & $>100$ & 2.71 \\
\hline S5 & $34(92.4)$ & $56.4(70.7)$ & $66.8(45.3)$ & $73.1(27.1)$ & 30.7 & 70.2 & $>100$ & $>100$ & 2.68 \\
\hline S6 & $34(92.4)$ & $62.1(56.2)$ & $73.3(26.6)$ & $77.6(10.5)$ & 30.7 & 88.4 & $>100$ & $>100$ & 1.94 \\
\hline
\end{tabular}

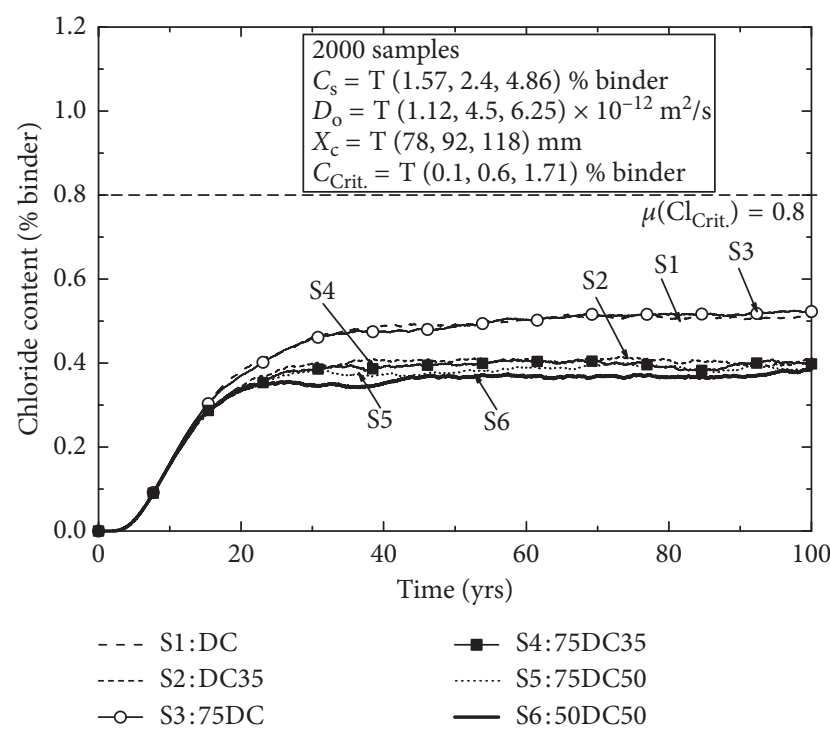

FIgURE 10: Mean profiles of chloride content with six proposed repair strategies.

judge the best repair strategy. This is because all of the mean profiles satisfy the corrosion-free condition. Hence, the use of the mean profiles as a criterion is not enough. Another factor, i.e., the total expected number of repair applications, is introduced here. By the same method used for S1 in Figure 9, the total expected number of repair applications, the mean and median of repair application time, and the percent confidence for all repair strategies are compared in Table 6. It is seen that S6 is the best, because the total expected number of repair applications is fewer. This agrees with the results from the deterministic assessment in Table 3 in the way that better repair material and deeper repair depth lead to fewer numbers of repairs. From Table 6, it is also observed that the number of repair applications is related to the percent confidence. For example, the total expected number of repair applications for S3 is equal to 2.92 as shown in the last column of Table 6 . The percent confidence for the first, second, and third repairs are larger than or approximately equal to $50 \%$, but that for the fourth one is lower than $50 \%$. This implies that if the percent confidence of the third repair is approximately equal to $50 \%$, then the total expected number of repair applications is almost thrice. It is also observed that if the percent confidence of any repair is high, e.g., 93.3\% of the first repair of $\mathrm{S} 4$, the mean of repair application time will not be much different from its median. But if the percent confidence is not high enough, e.g., $72.6 \%$ of the second repair of S3, its mean will be quite different from its median.

5.2.3. Sensitivity Analysis. In this study, the sensitivity analysis is used for observing the relative significance of four random variables, i.e., surface chloride $\left(C_{\mathrm{s}}\right)$, diffusion coefficient $\left(D_{\mathrm{o}}\right)$, cover depth $\left(X_{\mathrm{c}}\right)$, and critical chloride $\left(C_{\text {Crit }}\right)$, on probabilistic parameters. The probabilistic parameters are composed of the chloride content, the mean and median of corrosion initiation time, the total expected number of repair applications, and the median of repair application time. To perform the sensitivity analysis, the proposed descriptors, i.e., minimum, mode, and maximum in Table 1, will be added or subtracted so that either their mean or their standard deviation are disturbed by $10 \%$ as shown in $\mathrm{Ta}-$ bles 7 and 8, respectively.

Without repair, the sensitivity of the mean profiles of chloride content to the mean and the standard deviation of $C_{\mathrm{s}}$ is shown in the left-handed and right-handed figures of Figure 11, respectively. It is found that the mean profiles are directly related to the mean of $C_{s}$, but not sensitive to the standard deviation of $C_{s}$.

The sensitivity of the mean and the median of corrosion initiation time to the mean and the standard deviation of four random variables is shown in Figure 12. Its $x$-axis shows the corrosion initiation time for the case without disturbance, while its $y$-axis shows that with disturbance. From Figure 12(a), the mean of corrosion initiation time is most sensitive to the mean of $X_{c}$, because the difference between the means of corrosion initiation time without and with disturbance falls approximately on $15 \%$ margin of error. However, it is quite sensitive to the mean of the other three random variables, because the difference falls within $10 \%$ margin of error. In addition, the median of corrosion initiation time is most sensitive to the mean of $X_{c}$ (on $20 \%$ margin of error), but quite sensitive to the mean of the other random variables (on 10\% margin of error). These observations show that $X_{\mathrm{c}}$ (cover depth) is the most important parameter in design of new concrete structures to extend the corrosion initiation time. From Figure 12(b), the mean and the median of corrosion initiation time are however not sensitive to the standard deviation of all four random variables.

With repairs, the sensitivity of the total expected number of repair applications by six repair strategies to the mean of the four random variables is shown in Figure 13. It reveals 
TABLE 7: Descriptors for sensitivity analysis of the mean of four random variables.

\begin{tabular}{lcccc}
\hline Random variables & Disturbance & Descriptors & $\mu$ & $\sigma$ \\
\hline$C_{\mathrm{s}}(\%$ binder $)$ & $\mu\left(C_{\mathrm{S}}\right)+10 \% \mu\left(C_{\mathrm{S}}\right)$ & $\mathrm{T}(1.86,2.69,5.15)$ & 3.24 & 0.22 \\
& $\mu\left(C_{\mathrm{S}}\right)-10 \% \mu\left(C_{\mathrm{S}}\right)$ & $\mathrm{T}(1.28,2.11,4.57)$ & 2.65 & 0.7 \\
$D_{\mathrm{o}}\left(\times 10^{-12} \mathrm{~m}^{2} / \mathrm{s}\right)$ & $\mu\left(D_{0}\right)+10 \% \mu\left(D_{0}\right)$ & $\mathrm{T}(1.52,4.9,6.65)$ & 4.35 & 0.26 \\
& $\mu\left(D_{0}\right)-10 \% \mu\left(D_{0}\right)$ & $\mathrm{T}(0.72,4.1,5.85)$ & 3.56 & 1.06 \\
$X_{\mathrm{c}}(\mathrm{mm})$ & $\mu\left(X_{\mathrm{c}}\right)+10 \% \mu\left(X_{\mathrm{c}}\right)$ & $\mathrm{T}(88,102,128)$ & 0.24 \\
& $\mu\left(X_{\mathrm{c}}\right)-10 \% \mu\left(X_{\mathrm{c}}\right)$ & $\mathrm{T}(68,82,108)$ & 0.3 & 0.079 \\
$C_{\text {Crit }}(\%$ binder $)$ & $\mu\left(C_{\text {Crit }}\right)+10 \% \mu\left(C_{\text {Crit }}\right)$ & $\mathrm{T}(0.18,0.68,1.79)$ & 0.88 & 0.096 \\
& $\mu\left(C_{\text {Crit }}\right)-10 \% \mu\left(C_{\text {Crit }}\right)$ & $\mathrm{T}(0.02,0.52,1.63)$ & 0.72 & 0.34 \\
\hline
\end{tabular}

$\mathrm{T}(a, b, c)$ means triangular distribution with minimum, mode, and maximum of $a, b$, and $c$, respectively.

TABLE 8: Descriptors for sensitivity analysis of the standard deviation of four random variables.

\begin{tabular}{|c|c|c|c|c|c|}
\hline Random variables & Disturbance & Descriptors & $\mu$ & $\sigma$ & $\mathrm{COV}$ \\
\hline \multirow{2}{*}{$C_{\mathrm{s}}(\%$ binder $)$} & $\sigma\left(C_{S}\right)+10 \% \sigma\left(C_{S}\right)$ & $\mathrm{T}(1.64,2.4,4.79)$ & \multirow{2}{*}{2.94} & 0.67 & 0.23 \\
\hline & $\sigma\left(C_{\mathrm{S}}\right)-10 \% \sigma\left(C_{\mathrm{S}}\right)$ & $\mathrm{T}(1.5,2.4,4.93)$ & & 0.73 & 0.25 \\
\hline \multirow{2}{*}{$D_{\mathrm{o}}\left(\times 10^{-12} \mathrm{~m}^{2} / \mathrm{s}\right)$} & $\sigma\left(D_{0}\right)+10 \% \sigma\left(D_{0}\right)$ & $\mathrm{T}(1.23,4.5,6.14)$ & \multirow{2}{*}{3.96} & 1.02 & 0.26 \\
\hline & $\sigma\left(D_{0}\right)-10 \% \sigma\left(D_{0}\right)$ & $\mathrm{T}(1.01,4.5,6.36)$ & & 1.11 & 0.28 \\
\hline \multirow{2}{*}{$X_{\mathrm{c}}(\mathrm{mm})$} & $\sigma\left(X_{c}\right)+10 \% \sigma\left(X_{c}\right)$ & $\mathrm{T}(79,92,117)$ & \multirow{2}{*}{96} & 7.88 & 0.082 \\
\hline & $\sigma\left(X_{c}\right)-10 \% \sigma\left(X_{c}\right)$ & $\mathrm{T}(77,92,119)$ & & 8.69 & 0.091 \\
\hline \multirow{2}{*}{$C_{\text {Crit }}(\%$ binder $)$} & $\sigma\left(C_{\text {Crit }}\right)+10 \% \sigma\left(C_{\text {Crit }}\right)$ & $\mathrm{T}(0.13,0.6,1.68)$ & \multirow{2}{*}{0.8} & 0.32 & 0.40 \\
\hline & $\sigma\left(C_{\text {Crit }}\right)-10 \% \sigma\left(C_{\text {Crit }}\right)$ & $\mathrm{T}(0.07,0.6,1.74)$ & & 0.35 & 0.44 \\
\hline
\end{tabular}

$\mathrm{T}(a, b, c)$ means triangular distribution with minimum, mode, and maximum of $a, b$, and $c$, respectively.
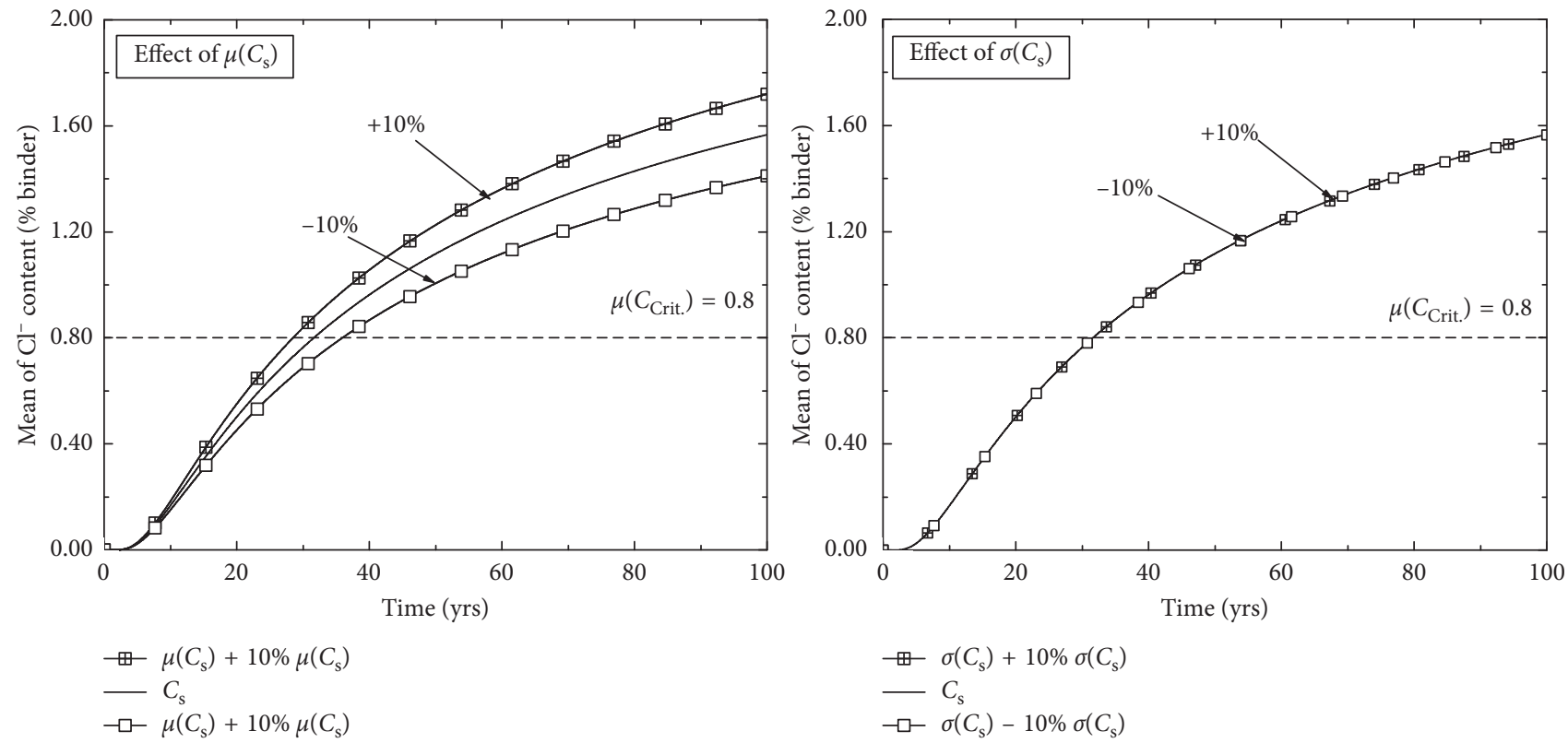

FIGURE 11: Sensitivity of $C_{\mathrm{s}}$ to chloride profiles in concrete without repair.

that the total expected number of repair applications is most sensitive to the mean of $X_{c}$ (on $20 \%$ margin of error) and quite sensitive to the mean of the other random variables (on $10 \%$ margin of error). Figure 14 shows the sensitivity of the median of the second repair application time to $10 \%$ disturbance of the mean of the four random variables. It reveals that the median of the second repair application time is most sensitive to the mean of $X_{c}$. By the same method, it can be shown that the total expected number of repair applications and the median of repair application time are not sensitive to the standard of the four random variables, because the difference is less than $2 \%$ margin of error.

\section{Conclusion}

In this paper, a study on probabilistic and sensitivity analysis of the service life (or time to repairs) for corrosion-free condition of chloride-attacked concrete structures with 


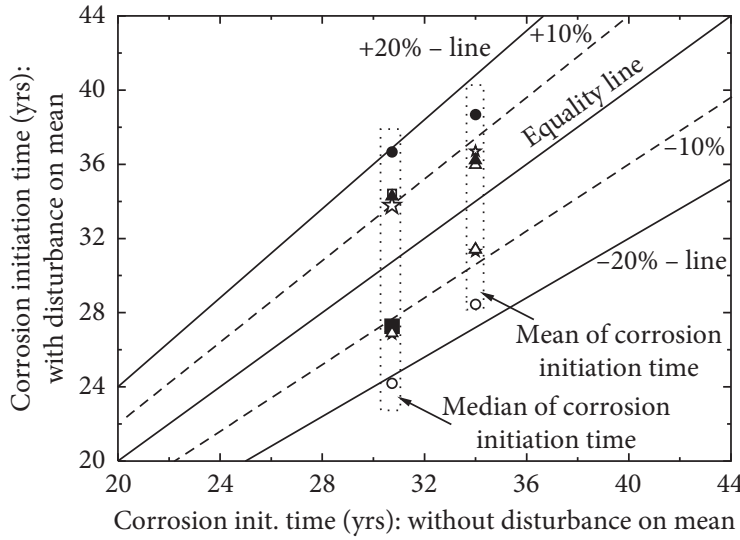

\ $\mu\left(C_{\mathrm{s}}\right)+10 \% \mu\left(C_{\mathrm{s}}\right)$

$\Delta \mu\left(C_{\mathrm{s}}\right)-10 \% \mu\left(C_{\mathrm{s}}\right)$

$\star \mu\left(D_{\mathrm{o}}\right)+10 \% \mu\left(D_{\mathrm{o}}\right)$

$\star \mu\left(D_{\mathrm{o}}\right)-10 \% \mu\left(D_{\mathrm{o}}\right)$

(a)

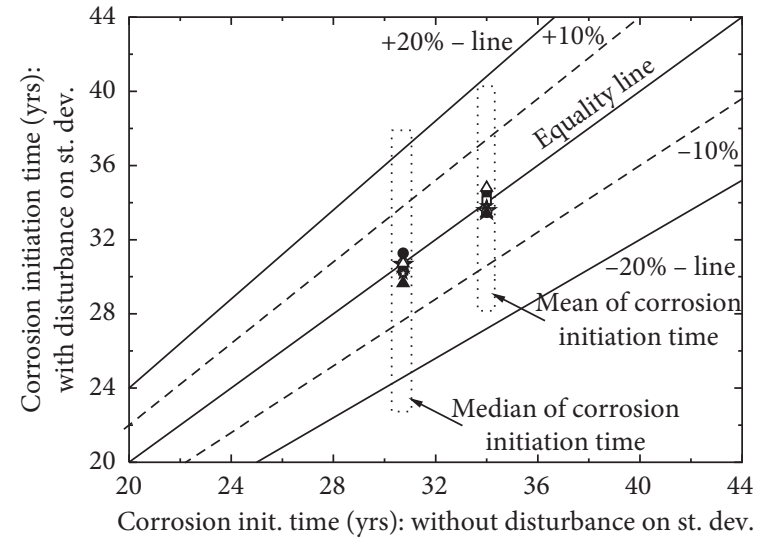

- $\sigma\left(C_{\mathrm{s}}\right)+10 \% \sigma\left(C_{\mathrm{s}}\right)$

- $\sigma\left(C_{\mathrm{s}}\right)-10 \% \sigma\left(C_{\mathrm{s}}\right)$

- $\sigma\left(X_{\mathrm{c}}\right)+10 \% \sigma\left(X_{\mathrm{c}}\right)$

$\star \sigma\left(D_{\mathrm{o}}\right)+10 \% \sigma\left(D_{\mathrm{o}}\right)$

t $\sigma\left(D_{\mathrm{o}}\right)-10 \% \sigma\left(D_{\mathrm{o}}\right)$

- $\sigma\left(X_{\mathrm{c}}\right)-10 \% \sigma\left(X_{\mathrm{c}}\right)$

А $\sigma\left(C_{\text {Crit }}\right)+10 \% \sigma\left(C_{\text {Crit }}\right)$

$\Delta \sigma\left(C_{\text {Crit }}\right)-10 \% \sigma\left(C_{\text {Crit }}\right)$

(b)

Figure 12: Sensitivity to mean and median of corrosion initiation time. (a) Effect of the mean of four random variables. (b) Effect of the standard deviation of four random variables.
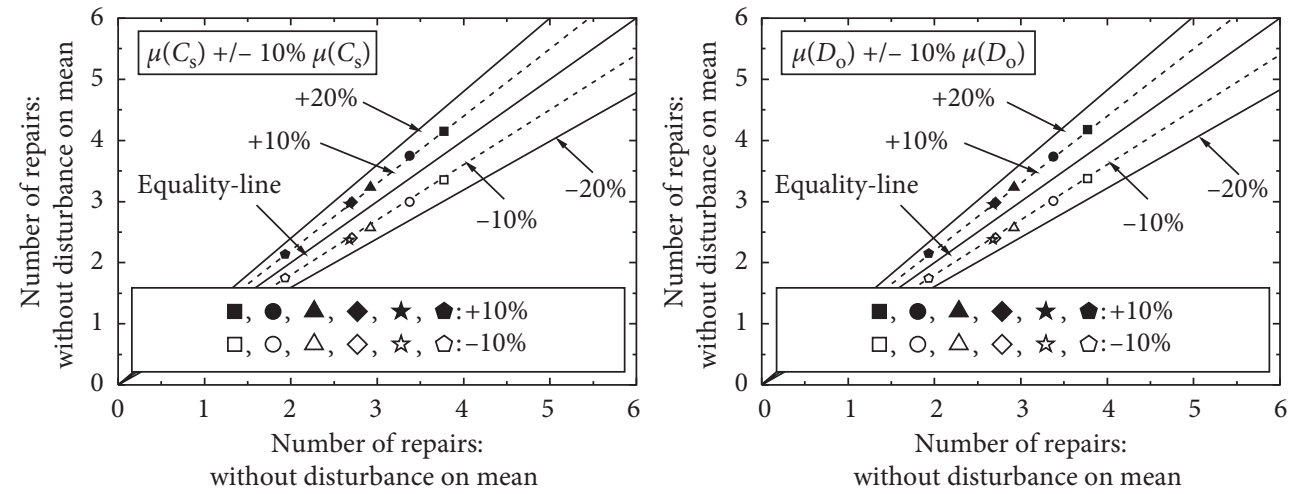
—, $\square$ S1:DC
$\diamond, \diamond$ S4:75DC35
-, O S2:DC35
$\star$, t $55: 75 \mathrm{DC} 50$
$\Delta, \triangle \mathrm{S} 3: 75 \mathrm{DC}$
- 口 S6:50DC50
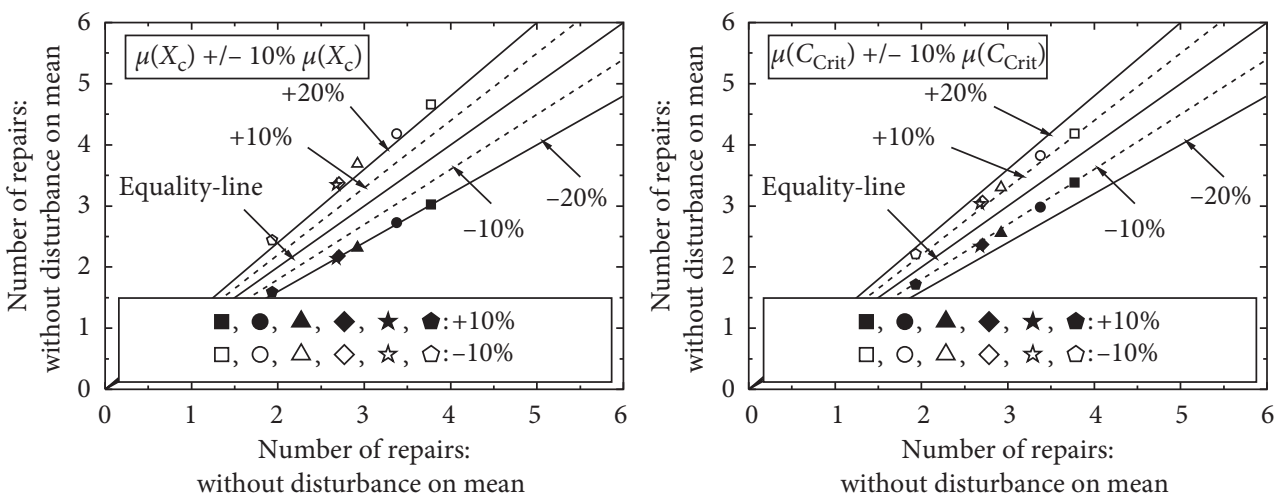

घ, $\square \mathrm{S} 1: \mathrm{DC}$

$\diamond, \diamond$ S4:75DC35

-, O S2:DC35

$\star$, 放 S5:75DC50

A, $\triangle \mathrm{S} 3: 75 \mathrm{DC}$

-, 口 S6:50DC50

- $\square \mathrm{S} 1: \mathrm{DC}$

-, O S2:DC35

$\triangle \mathrm{S} 3: 75 \mathrm{DC}$ $\diamond, \diamond$ S4:75DC35

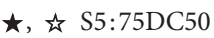

-, 口 S6:50DC50

FIgURE 13: Sensitivity of the mean of four random variables to the total expected number of repair applications. 

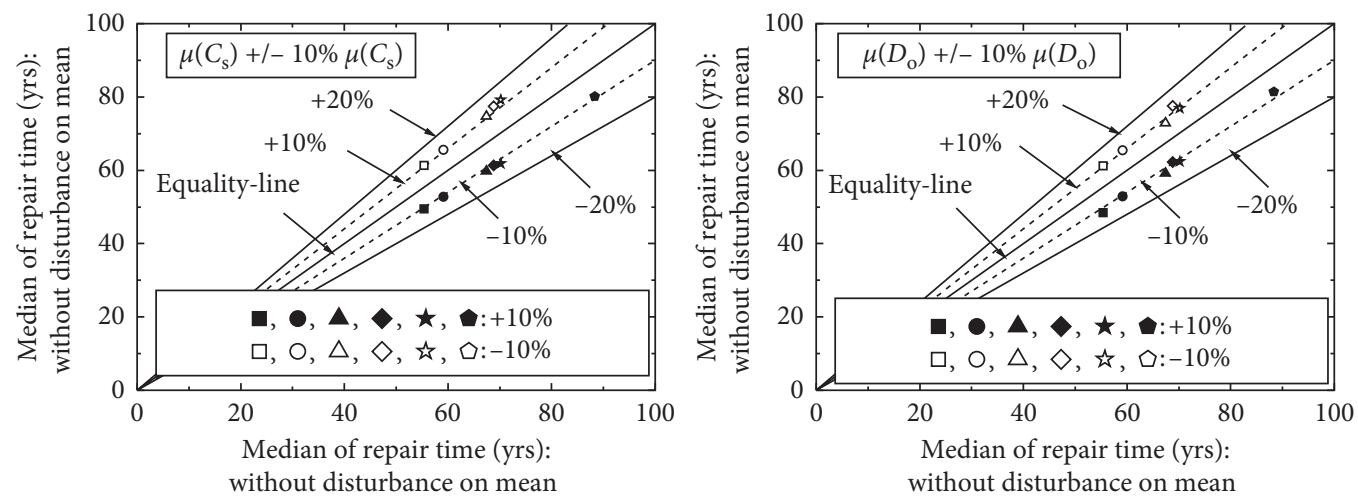
-, $\square \mathrm{S} 1: \mathrm{DC}$
$\diamond, \diamond$ S4:75DC35
-, O S2:DC35
$\star$, 论 S5:75DC50
A, $\triangle \mathrm{S} 3: 75 \mathrm{DC}$
-. 口 S6:50DC50
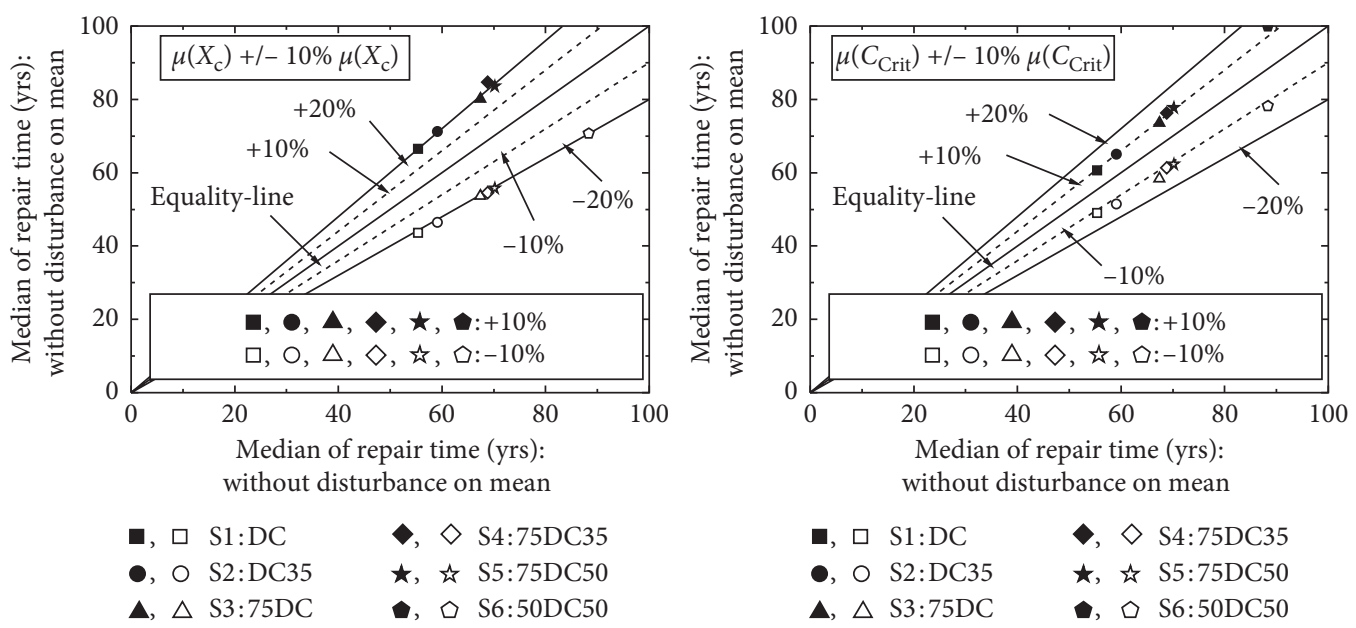

FIGURE 14: Sensitivity of the mean of four random variables to the median of second repair application time.

multiple repairs is carried out. Four groups of probabilistic parameters are studied: i.e., (1) time-dependent chloride content, (2) mean and median of corrosion initiation and repair application times, (3) percent confidence of repairs, and (4) the total expected number of repairs. For these, four governing random variables (surface chloride, diffusion coefficient, concrete cover depth, and critical chloride value) and six repair strategies are considered. By using the proposed computational approach, observations can be found as follows:

(1) Both the deterministic and probabilistic studies show that better repair material and deeper repair depth lead to fewer numbers of repairs.

(2) If only the deterministic assessment is utilized, the corrosion initiation time is predicted as a discrete time. This however reveals that corrosion-free planning of concrete structures with long-term repairs, which require the expected (or probabilistic) repair application time, cannot properly be carried out. This is due to the fact that the expected number of concrete structures with reinforcement corrosion cannot be determined.
(3) The time-dependent dispersion of chloride content should be calculated in terms of the coefficient of variation rather than the standard deviation.

(4) There are two approaches to assess the service life, i.e., the mean and standard deviation of repair application time, and the median (or 50-percentile) of repair application time. The median is found to be more effective, because it is not sensitive to the design time period.

(5) For existing concrete structures under chloride attack, it seems that the depth of repairs is more effective in reducing the mean profiles of chloride content than the quality of repair materials. However, the excessive depth of repairs is not always recommended due to another control factor, such as the immediate amount of redistributing chloride ions at the repair depth. It is also noted that, in practice, other factors, such as the cost of repairs and etc., are also found to control the repair strategy. To alleviate this limitation, this study however proposes to consider a terminology called the total expected number of repair applications. 
(6) The mean and median of repair application time (including corrosion initiation time) and the total expected number of repair applications are most sensitive to the mean of the cover depth, but not sensitive to the standard deviation of all four random variables. Therefore, the cover depth is the most important parameter in design of new concrete structures exposed to chloride environment in order to extend the repair application time as well as corrosion initiation time.

(7) There are two recommendations for further study. For the first recommendation, other control factors, such as the cost of repairs, should be taken into account, because it plays an important role for decision makers to obviously compare different repair strategies. For the second recommendation, the flexural cracking of concrete members, such as beams, due to serviceability loads requires further study, because cracks caused by mechanical loads reduce the chloride resistance of concrete and speed up the initiation of steel corrosion in concrete, which frequently occurs in field applications [44].

\section{Data Availability}

Previously reported raw data were used to support this study and are available at https://doi.org/10.1016/j.conbuildmat. 2009.05.007. This prior study is cited at relevant places within the text as reference [42], and the probabilistic data used to support the findings of this study are also included within the article.

\section{Conflicts of Interest}

The author declares that there are no conflicts of interest.

\section{Acknowledgments}

This research was funded by King Mongkut's University of Technology North Bangkok (contract no. KMUTNB-61GOV-B-16). The author would also like to acknowledge Ms. Paweena Narupankulchai for assisting in data collections.

\section{References}

[1] M. Sun, W. J. Staszewski, and R. N. Swamy, "Smart sensing technologies for structural health monitoring of civil engineering structures," Advances in Civil Engineering, vol. 2010, Article ID 724962, 13 pages, 2010.

[2] N. Damrongwiriyanupap, S. Limkatanyu, and Y. Xi, “A thermo-hygro-coupled model for chloride penetration in concrete structures," Advances in Materials Science and Engineering, vol. 2015, Article ID 682940, 10 pages, 2015.

[3] C. L. Page, "Mechanism of corrosion protection in reinforced concrete marine structures," Nature, vol. 258, no. 5535, pp. 514-515, 1975.

[4] I. Sæther, "Bond deterioration of corroded steel bars in concrete," Structure and Infrastructure Engineering, vol. 7, no. 6, pp. 415-429, 2011.

[5] G. G. Triantafyllou, T. C. Rousakis, and A. I. Karabinis, "Corroded RC beams patch repaired and strengthened in flexure with fiber-reinforced polymer laminates," Composites Part B: Engineering, vol. 112, pp. 125-136, 2017.

[6] A. Petcherdchoo, "Pseudo-coating model for predicting chloride diffusion into surface-coated concrete in tidal zone: Time-dependent approach," Cement and Concrete Composites, vol. 74, pp. 88-99, 2016.

[7] R. D. Hooton, M. R. Geiker, and E. C. Bentz, "Effects of curing on chloride ingress and implications on service life," ACI Materials Journal, vol. 99, no. 2, pp. 201-206, 2002.

[8] W. Sanawung, T. Cheewaket, W. Tangchirapat, and C. Jaturapitakkul, "Influence of palm oil fuel ash and W/B ratios on compressive strength, water permeability, and chloride resistance of concrete," Advances in Materials Science and Engineering, vol. 2017, Article ID 4927640, 8 pages, 2017.

[9] B. Dong, Z. Gu, Q. Qiu et al., "Electrochemical feature for chloride ion transportation in fly ash blended cementitious materials," Construction and Building Materials, vol. 161, pp. 577-586, 2018.

[10] J. Paulsson-Tralla, "Service life prediction of concrete bridge decks repaired with bonded concrete overlays," Materials and Structures, vol. 34, no. 1, pp. 34-41, 2001.

[11] Y. Li and T. Vrouwenvelder, "Service life prediction and repair of concrete structures with spatial variability," Heron, vol. 52, pp. 251-67, 2007.

[12] M. D. Pritzl, H. Tabatabai, and A. Ghorbanpoor, "Laboratory assessment of select methods of corrosion control and repair in reinforced concrete bridges," International Journal of Corrosion, vol. 2014, Article ID 175094, 11 pages, 2014.

[13] Maunsell Ltd., Optimum Maintenance Strategies for Different Bridge Type, Highway Agency, Guildford, UK, 2000.

[14] P. Duan, C. Yan, and W. Luo, "A novel waterproof, fast setting and high early strength repair material derived from metakaolin geopolymer," Construction and Building Materials, vol. 124, pp. 69-73, 2016.

[15] A. Petcherdchoo, "Closed-form solutions for modeling chloride transport in unsaturated concrete under wet-dry cycles of chloride attack," Construction and Building Materials, vol. 176, pp. 638-651, 2018.

[16] A. A. Abouhussien and A. A. A. Hassan, "Experimental and empirical time to corrosion of reinforced concrete structures under different curing conditions," Advances in Civil Engineering, vol. 2014, Article ID 595743, 9 pages, 2014.

[17] A. Petcherdchoo, "Service life and environmental impact due to repairs by metakaolin concrete after chloride attack," in RILEM Bookseries, pp. 35-41, Springer Nature, Basel, Switzerland, 2015.

[18] A. Petcherdchoo, "Repairs by fly ash concrete to extend service life of chloride-exposed concrete structures considering environmental impacts," Construction and Building Materials, vol. 98, pp. 799-809, 2015.

[19] REHABCON, "Final report on the evaluation of alternative repair and upgrading options: strategy for maintenance and rehabilitation in concrete structures," EC Innovation and SME Programme Project No. IPS-2000-0063, Department of Building Materials, LIT, Lund, Sweden, 2004.

[20] A. Petcherdchoo, "Environmental impacts of combined repairs on marine concrete structures," Journal of Advanced Concrete Technology, vol. 13, no. 3, pp. 205-213, 2015.

[21] J. Crank, The Mathematics of Diffusion, The ClarendonPress, Oxford, UK, 1975.

[22] M. K. Kassir and M. Ghosn, "Chloride-induced corrosion of reinforced concrete bridge decks," Cement and Concrete Research, vol. 32, no. 1, pp. 139-143, 2002. 
[23] A. Petcherdchoo, "Closed-form solutions for bilinear surface chloride functions applied to concrete exposed to deicing salts," Cement and Concrete Research, vol. 102, pp. 136-148, 2017.

[24] J. Zhang and Z. Lounis, "Sensitivity analysis of simplified diffusion-based corrosion initiation model of concrete structures exposed to chlorides," Cement and Concrete Research, vol. 36, no. 7, pp. 1312-1323, 2006.

[25] E. Bastidas-Arteaga, A. Chateauneuf, M. Sánchez-Silva, P. Bressolette, and F. Schoefs, "Influence of weather and global warming in chloride ingress into concrete: a stochastic approach," Structural Safety, vol. 32, no. 4, pp. 238-249, 2010.

[26] J. Hackl and J. Kohler, "Reliability assessment of deteriorating reinforced concrete structures by representing the coupled effect of corrosion initiation and progression by Bayesian networks," Structural Safety, vol. 62, pp. 12-23, 2016.

[27] L. Pang and Q. Li, "Service life prediction of RC structures in marine environment using long term chloride ingress data: comparison between exposure trials and real structure surveys," Construction and Building Materials, vol. 113, pp. 979-987, 2016.

[28] L. Yang, K. Li, and X. Pang, "Design and optimization of maintenance strategies for a long life-span port project," Materials and Structures, vol. 46, no. 1-2, pp. 161-172, 2013.

[29] A. Petcherdchoo, "Probabilistic assessment of $\mathrm{CO}_{2}$ due to concrete repairs for crack-free condition of marine concrete structures," Advanced Materials Research, vol. 931-932, pp. 426-430, 2014.

[30] A. Rahimi, C. Gehlen, T. Reschke, and A. Westendarp, "Approaches for modelling the residual service life of marine concrete structures," International Journal of Corrosion, vol. 2014, Article ID 432472, 11 pages, 2014.

[31] V. A. Saetta, V. R. Scotta, and V. R. Vitaliani, "Analysis of chloride diffusion into partially saturated concrete," $A C I$ Materials Journal, vol. 90, no. 5, pp. 441-51, 1993.

[32] K. Uji, Y. Matsuoka, and T. Maruya, "Formulation of an equation for surface chloride content of concrete due to permeation of chloride," in Corrosion of Reinforcement in Concrete, C. L. Page, K. W. J. Treadaway, and P. B. Bamforth, Eds., SCI, London, UK, 1990.

[33] A. Costa and J. Appleton, "Chloride penetration into concrete in marine environment-part II: prediction of long term chloride penetration," Materials and Structures, vol. 32, no. 5, pp. 354-359, 1999.

[34] A. Petcherdchoo, "Time dependent models of apparent diffusion coefficient and surface chloride for chloride transport in fly ash concrete," Construction and Building Materials, vol. 38, pp. 497-507, 2013.

[35] P. Skoglund, J. Silfwerbrand, J. Holmgren, and J. Trägårdh, "Chloride redistribution and reinforcement corrosion in the interfacial region between substrate and repair concrete-a laboratory study," Material and Structures, vol. 41, no. 6, pp. 1001-1014, 2008.

[36] W. H. Press, S. A. Teukolsky, W. T. Vetterling, and B. P. Flannery, Numerical Recipes in C: the Art of Scientific Computing, Cambridge University Press, Cambridge, UK, 1999.

[37] O. Truc, J. P. Ollivier, and L. O. Nilsson, "Numerical simulation of multi-species transport through saturated concrete during a migration test - MsDiff code," Cement and Concrete Research, vol. 30, no. 10, pp. 1581-1592, 2000.

[38] F. Deby, M. Carcassès, and A. Sellier, "Probabilistic approach for durability design of reinforced concrete in marine environment," Cement and Concrete Research, vol. 39, no. 5, pp. 466-471, 2009.

[39] L. C. Neves, Life cycle analysis of bridges considering condition, safety, and maintenance cost interaction, Ph.D. thesis, University of Minho, Guimarães, Portugal, 2005.

[40] M. McKay, W. Conover, and R. A. Beckman, "Comparison of three methods for selecting values of input variables in the analysis of output from a computer code," Technometrics, vol. 21, no. 2, pp. 239-245, 1979.

[41] A. Olsson, G. Sandberg, and O. Dahlblom, "On Latin Hypercube sampling for structural reliability analysis," Structural Safety, vol. 25, no. 1, pp. 47-68, 2003.

[42] H. W. Song, S. W. Pack, and K. Y. Ann, "Probabilistic assessment to predict the time to corrosion of steel in reinforced concrete tunnel box exposed to sea water," Construction and Building Materials, vol. 23, no. 10, pp. 3270-3278, 2009.

[43] A. Rahimi, C. Gehlen, T. Reschke, and A. Westendarp, "Chloride transport in concrete structural elements after repair," in Proceeding of the International ConcreteInnovation and Design: FIB Symposium 2015, Copenhagen, Denmark, May 2015.

[44] Q. Wang, W. Sun, L. Guo, C. Gu, and J. Zong, "Modeling chloride diffusion coefficient of steel fiber reinforced concrete under bending load," Advances in Civil Engineering, vol. 2018, Article ID 3789214, 6 pages, 2018. 


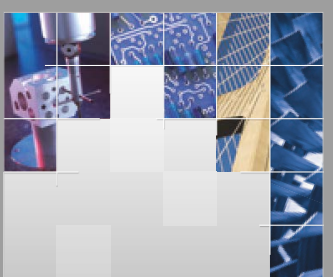

\section{Enfincering}
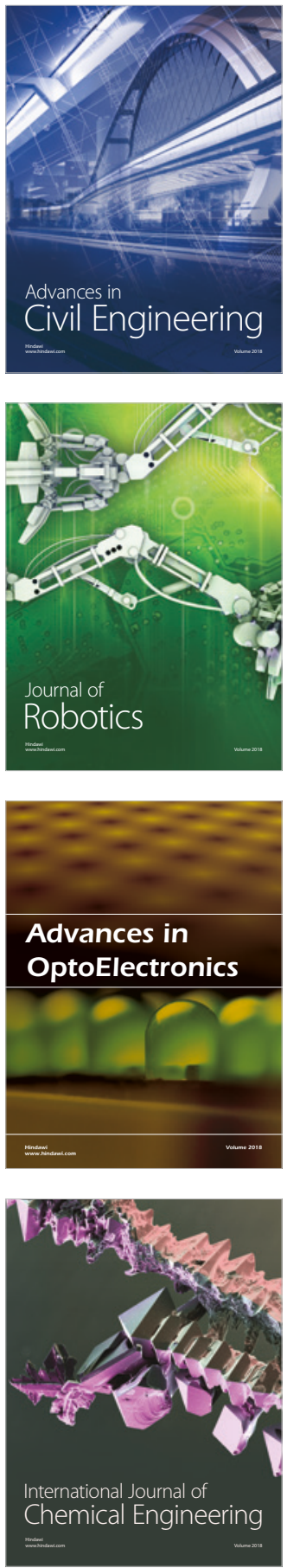

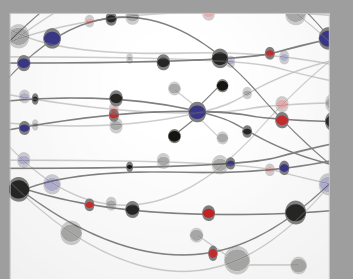

\section{Rotating \\ Machinery}

The Scientific World Journal

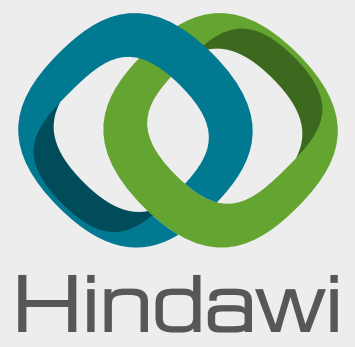

Submit your manuscripts at

www.hindawi.com
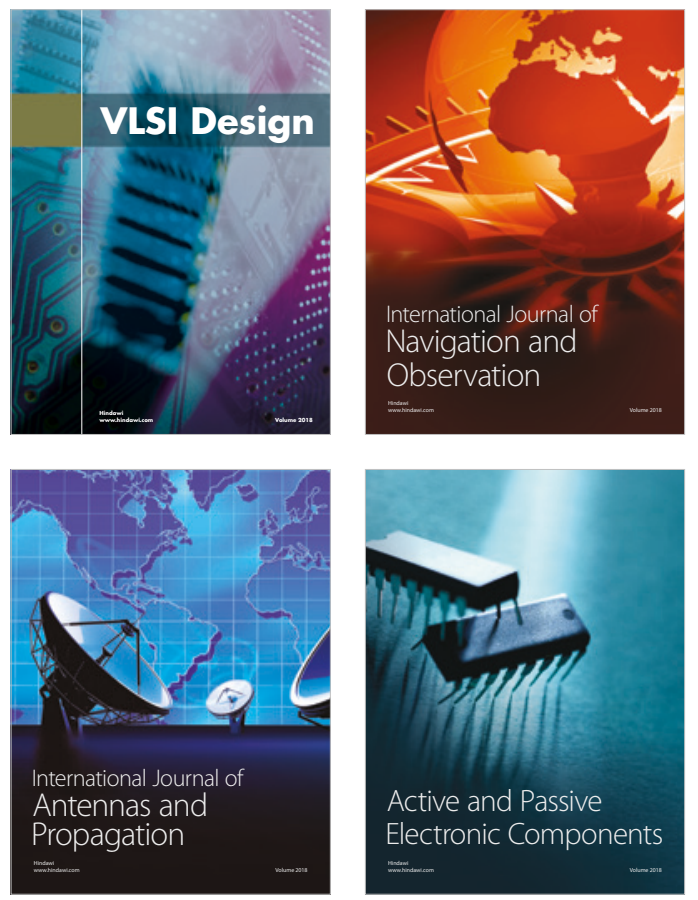
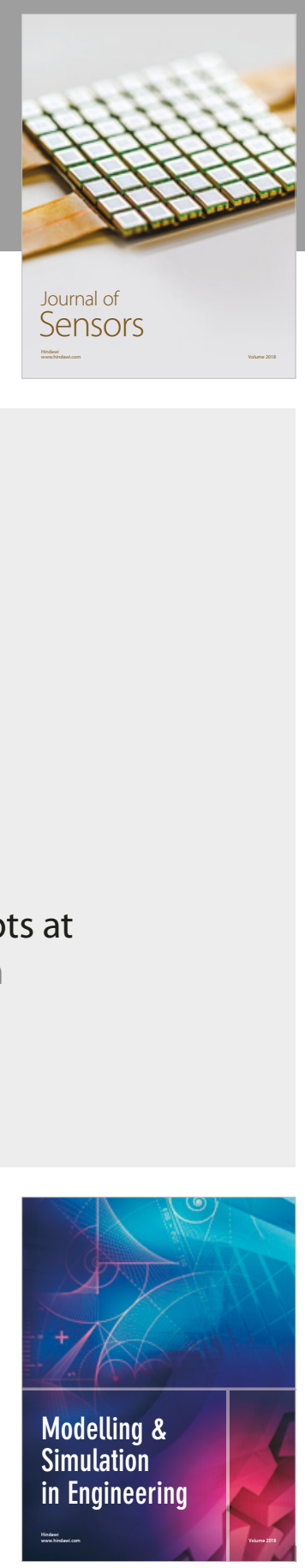

\section{Advances \\ Multimedia}
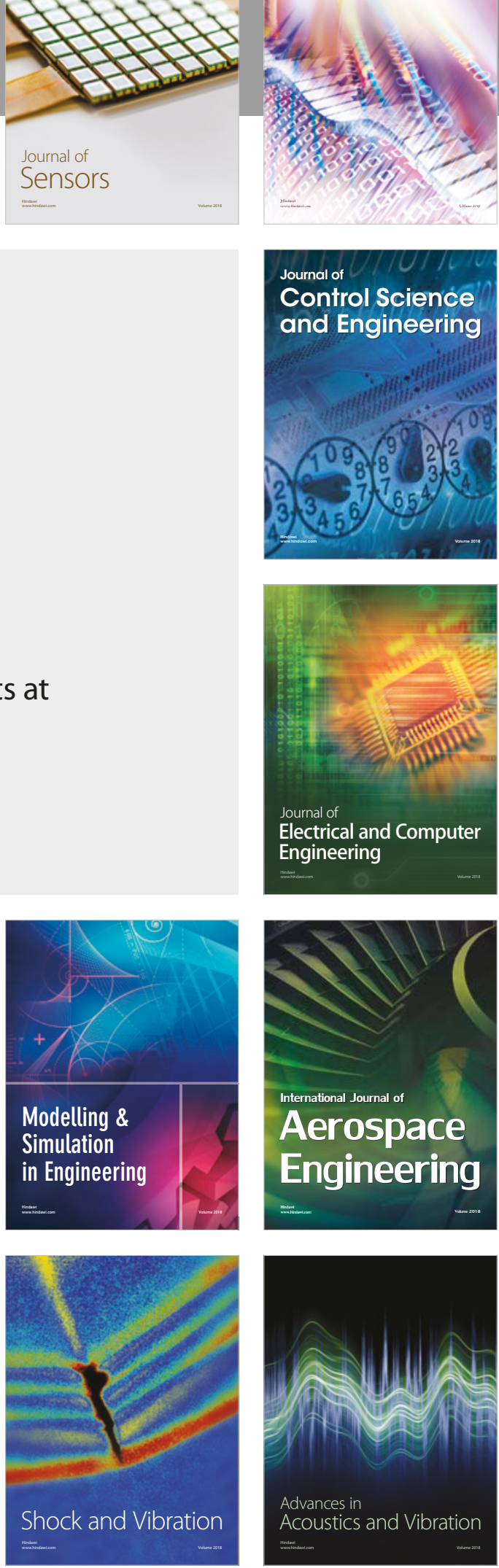